\title{
Impact of the Midlatitude Storm Track on the Upper Pacific Ocean
}

\author{
WiLCO HAZELEGER \\ Royal Netherlands Meteorological Institute, De Bilt, Netherlands \\ Richard Seager, Martin Visbeck, ANd NaOmi Naik \\ Lamont-Doherty Earth Observatory of Columbia University, Palisades, New York \\ KEITH RODGERS \\ Max-Planck-Institut für Meteorologie, Hamburg, Germany
}

(Manuscript received 19 November 1999, in final form 5 June 2000)

\begin{abstract}
Transient eddies in the atmosphere induce a poleward transport of heat and moisture. A moist static energy budget of the surface layer is determined from the NCEP reanalysis data to evaluate the impact of the storm track. It is found that the transient eddies induce a cooling and drying of the surface layer with a monthly mean maximum of $60 \mathrm{~W} \mathrm{~m}^{-2}$. The cooling in the midlatitudes extends zonally over the entire basin. The impact of this cooling and drying on surface heat fluxes, sea surface temperature (SST), water mass transformation, and vertical structure of the Pacific is investigated using an ocean model coupled to an atmospheric mixed layer model. The cooling by atmospheric storms is represented by adding an eddy-induced transfer velocity to the mean velocity in an atmospheric mixed layer model. This is based on a parameterization of tracer transport by eddies in the ocean. When the atmospheric mixed layer model is coupled to an ocean model, realistic SSTs are simulated. The SST is up to $3 \mathrm{~K}$ lower due to the cooling by storms. The additional cooling leads to enhanced transformation rates of water masses in the midlatitudes. The enhanced shallow overturning cells affect even tropical regions. Together with realistic SST and deep winter mixed layer depths, this leads to formation of homogeneous water masses in the upper North Pacific, in accordance to observations.
\end{abstract}

\section{Introduction}

The sea surface temperature (SST) forms the lower boundary condition for the atmosphere. Therefore, understanding of how the SST and its variability is generated is of prime importance for climate studies. The SST is modified by surface heat fluxes. Variability in the surface fluxes as well as changes in the ocean heat flux divergence drives variability in SST (e.g., Cayan 1992). This makes a good understanding of heat fluxes essential for climate studies. Also, from an oceanographic viewpoint surface heat fluxes are important. Heat fluxes drive water from one density to another in the mixed layer, leading to transformation of water masses (Walin 1982). Horizontal and temporal variations in the surface fluxes lead to variations in the mixed layer depth. This determines the amount of water that is subducted to the interior. Water mass transformation and

Corresponding author address: Dr. Wilco Hazeleger, Royal Netherlands Meteorological Institute (KNMI), P.O. Box 201, 3730 AE, De Bilt, Netherlands.

E-mail: hazelege@knmi.nl subduction determine the stratification of the ocean (Woods 1985; Marshall et al. 1998). The importance of the surface heat fluxes to the mean state and the variability of the ocean requires a good understanding of the fluxes and a good representation of them in numerical models. In this manuscript we study one aspect of the surface fluxes in the Pacific, that is, the effect of storm tracks on the heat fluxes and subsequently the effect on SST, water mass transformation, and the stratification of the ocean. The purpose of this paper is twofold. First, we diagnose the additional cooling due to atmospheric storms and determine an eddy-induced transfer velocity that can be used in atmospheric mixed layer models to account for the effect of storms. Then, the eddy-induced transfer velocity will be applied in a numerical model to study the impact of the storm tracks on the upper Pacific Ocean.

In this paper we will focus on the surface heat fluxes at the midlatitudes in the Pacific. This is a key region for climate variability because the subduction rates are large (Qiu and Huang 1995) and a positive ocean-atmosphere feedback may occur in this region (Latif and Barnett 1994). In this region transient atmospheric ed- 
dies form into localized, geographically fixed areas. These so-called storm tracks are located near the midlatitude atmospheric jet streams and, interestingly, also follow the regions of maximum meridional SST gradient. Here, the poleward and upward sloping isentropes provide available potential energy for the baroclinic instability process. The flattening of isentropes by baroclinic instability cause a transport of warm and moist air northward and cool dry air southward (Kushner and Held 1998). The northward sensible and latent heat transport in the atmosphere reflects this eddy-driven circulation. It cools and dries the surface layer at the midlatitudes (e.g., Valdes and Hoskins 1989). The impact of this cooling on the ocean is studied in this paper. Earlier studies with one-dimensional models by, for example, Camp and Eslberry (1978) have shown that the effect of individual storms on the oceanic mixed layer is large. They also indicate that nonlocal processes may be important. In a very idealized ocean model Polonsky et al. (1992) show a cooling of $1-2 \mathrm{~K}$ due to synoptic atmospheric variability. They emphasize the importance of horizontal oceanic inhomogeneity. Here we will use a much more elaborate three-dimensional ocean model to study the impact of storms.

Synoptic variability associated with the atmospheric transient eddies has a timescale of 2-10 days (Wallace et al. 1988). Alexander and Scott (1997) have studied the submonthly variability in the surface buoyancy fluxes. They showed that more than half of the total surface flux variability in winter in the region where storms are active occurs on timescales of less than 30 days. Variability on these short timescales is not always included in surface climatologies or simple models used to force ocean models (e.g., Seager et al. 1995; Kleeman and Power 1995). This requires parameterization of the submonthly variability. Here, we present a parameterization of the impact of storm tracks on the surface fluxes based on the parameterization of eddies in the ocean according to Gent and McWilliams (1990). That is, an eddy-induced advection is used to parameterize the effect of eddies on temperature and humidity. Kushner and Held (1998) have shown that such an approach is applicable to the atmosphere. First, we will present a moist static energy budget of the atmospheric surface layer to clarify the spatial and temporal structure of the eddy fluxes. Then the parameterization will be tested in an atmospheric mixed layer model. In this model the turbulent fluxes are determined through a balance of horizontal advection and diffusion, the surface flux and the flux at the mixed layer top, and, for temperature, radiative cooling. The latent heat, sensible heat, and longwave radiation fluxes can evolve freely. Furthermore, the temperature and humidity are internally generated in the model. Therefore, this is a suitable model to test the effect of the cooling by storms. Instead of parameterizing the eddy-induced transfer velocity itself, we will specify it according to the National Centers for Environmental Prediction-National Center for Atmospheric
Research (NCEP-NCAR) 40-year reanalysis data (Kalnay et al. 1996). Thus the position and strength of the storm tracks remain constant (except for a seasonal cycle). However, the gradients upon which the additional velocity acts are internally determined by the model. By including the parameterization, the tendency to moisten and warm the boundary layer through increased ocean-atmosphere surface fluxes due to storms is also explicitly simulated. After validation of the parameterization, it is subsequently used to study the effect of the storm tracks on the ocean using an oceanic general circulation model.

This manuscript is organized as follows. In section 2 the moist static energy of the surface layer of the atmosphere is presented using NCEP-NCAR reanalysis data. Then the parameterization of the impact of the storm tracks on the surface fluxes is presented in section 3. In section 4 the models are presented, and in section 5 the impact of the storm track on the heat fluxes, SST, water mass transformation, and the interior of the ocean. Finally in 6 a summary is given and conclusions are drawn.

\section{Moist static energy budget of the lower atmosphere}

In order to study the effect of the atmospheric eddies on the surface fluxes we will first present a moist static energy budget of the lower atmosphere. We focus on moist static energy because it is a conserved quantity for air masses and because it combines the effects of humidity and temperature. The budget gives insight in the processes that determine the surface fluxes. Such a budget for the atmospheric mixed layer has been presented by Seager et al. (2000). There, the focus was on anomalies related to the North Atlantic Oscillation. Here, we show the budget for the mean fields in the Pacific.

The moist static energy is defined as

$$
S=g z+c_{p} \theta+L_{v} q
$$

with $g$ the gravitational constant, $z$ the height, $c_{p}$ the heat capacity of air, $\theta$ the potential temperature, $L_{v}$ the latent heat, and $q$ the specific humidity. We consider a layer between the surface $(1000 \mathrm{hPa})$ and $925 \mathrm{hPa}$ (the second level of the NCEP-NCAR reanalysis data). The layer is assumed to be in steady state. This is justified by the fast adjustment of the near-surface air temperature to SST (Boers and Betts 1988). This is confirmed by the high correlation between the monthly mean air temperature and SST in the NCEP-NCAR reanalysis data. The correlation is well above 0.6 almost everywhere in the Pacific (not shown). The vertical integral of the moist static energy equation, in pressure coordinates, over this layer is 


$$
\begin{aligned}
& \frac{1}{g}\left(P \mathbf{u} \cdot \nabla S-\omega_{B}\left(S_{B}-S\right)+P \boldsymbol{\nabla} \cdot\left(\overline{\mathbf{u}^{\prime} S^{\prime}}\right)-\overline{\omega^{\prime} S^{\prime}}{ }_{B}\right) \\
& \quad=\frac{\omega_{0}}{g}\left(S_{0}-S\right)+\frac{1}{g} \overline{\left(\omega^{\prime \prime} S^{\prime \prime}\right)_{B}}+\frac{1}{g} c_{p} P R .
\end{aligned}
$$

Here the subscript $B$ stands for the top of the layer, the subscript 0 stands for the surface; $P$ is the pressure thickness, $\mathbf{u}=(u, v)$ is the wind vector, $\omega$ is the vertical pressure velocity, and $R$ is the radiative cooling. The primes stand for the deviation from the monthly mean. The double primes represent the turbulent fluxes. We analyze the terms in Eq. (2) using the NCEP-NCAR reanalysis data from January 1958 to December 1998 (Kalnay et al. 1996). Monthly mean data has been used with a resolution of $2.5^{\circ}$. The last two terms in Eq. (2) cannot be determined from the data. Their combined effect balances the other terms and can be determined as a residual. Note that, when the last term is diagnosed as a residual, this term also includes errors in the calculation of the other terms. However, we expect the errors to be small since we use the same pressure levels as in the NCEP-NCAR reanalysis data. This excludes one of the major sources of errors in budget studies, that is, the vertical interpolation (see Alexander and Schubert 1990). Also, as argued above, the tendency of moist static energy can be omitted as it is small. Moreover, we do not focus on the residual, but rather on the covariances in the budget, which are explicitly carried in the NCEP-NCAR reanalysis data. The main source of error that remains is the error in the data itself. An estimate of that uncertainty can be obtained by making the budget with winds and heat fluxes from the Comprehensive Ocean-Atmosphere Data Set (COADS) data (Da Silva 1994). In this case the residual appeared to be about $20 \mathrm{~W} \mathrm{~m}^{-2}$ lower, but it has the same spatial distribution. The differences are mainly caused by lower surface heat fluxes in the COADS data.

Figure 1 shows the different terms of Eq. (2) in the Northern Hemisphere winter. We only show boreal winter values here because the signals are strongest then. Also the seasonal cycle is less strong in the Southern Hemisphere (see section 3). When discussing the storm track parameterization and the impact of the storms we will also address the results from the summer season. In Fig. 1a the horizontal advection of mean moist static energy is shown. The advection of cool and dry air is clear off the coast of Japan. Here northwesterly winds advect cool and dry air from the continent. It is notable that this advective effect is restricted to the region quite close to the coast. To the east of this region, southwesterly winds advect warm and moist air to the north. Equatorward of about $25^{\circ} \mathrm{N}$ the trade winds cause a cooling and drying of the air. The second term in Eq. (2) represents the vertical advection of moist static energy. This term has the sign of the vertical velocity at the top of the mixed layer (Fig. 1b). The rising and sinking of air in the Tropics and subtropics associated with the Hadley cell is the most prominent feature, and elsewhere the term is small. The covariances in Eq. (2) represent the atmospheric eddies, that is, variations on a submonth timescale. Figures $1 \mathrm{c}$ and $1 \mathrm{~d}$ show the effect of the eddies. When the horizontal and vertical eddy terms are added, the storm tracks become clear. The eddies cause a cooling and drying over the midlatitudes. The horizontal component shows that eddies transfer moist warm air northward and cool dry air southward. This results in a dipole pattern centered on the maximum SST gradient (around $35^{\circ} \mathrm{N}$ ). The vertical eddy component is everywhere of the same sign and reveals a cooling. The maximum of this cooling coincides with the maximum SST gradient. The patterns are consistent with results from Valdes and Hoskins (1989) and Swanson and Pierrehumbert (1997). They show a cooling by transient eddies extending over the entire North Pacific basin, with a maximum cooling around $170^{\circ} \mathrm{E}$ as well. In Figs. 1e and 1f the right-hand side terms of Eq. (2) are shown. Figure 1e shows the cooling by the surface fluxes. The latent heat flux is the largest contributor to the surface fluxes. Warming by the surface fluxes is largest in the Kuroshio region, consistent with previous studies (e.g., Cayan 1992). Finally, the residual term is shown in Fig. 1f. This term must be balanced by radiative cooling and turbulent entrainment at the top of the layer. The residual term is mainly balanced by entrainment at the top of the mixed layer, because the radiative cooling is relatively uniform and small $[O(50$ $\mathrm{W} \mathrm{m}^{-2}$ )]. Essentially the same picture arises in the Southern Hemisphere during austral winter (not shown). In the Tropics the moist static energy budget is essentially a balance between surfaces fluxes and entrainment at the top of the mixed layer (e.g., Seager et al. 1995).

The high outgoing surface fluxes to the east of Japan during winter have often been attributed to advection of cool and dry air from the continent over warm surface waters in the western boundary currents (e.g., Cayan 1992). The budget analysis shows that horizontal advection cannot balance the warming and moistening by surface fluxes (compare Fig. 1a with Fig. 1e) and, instead, atmospheric eddies make an equal contribution. Furthermore, there is a large contribution from the entrainment of dry air at the top of the mixed layer that is included in the residual term. This is most likely indicative of active deep or shallow convection, hardly surprising given the enormous air-sea thermodynamic disequilibrium in this region.

The previous analysis shows that the surface fluxes are balanced by different processes. The atmospheric eddies are found to contribute significantly in the midlatitudes. In the next section we will present a parameterization for the impact of the eddies on the heat budget. Then the effect of the storm tracks on oceanic variables will be determined by implementing the parameterization in a simple model of the atmospheric mixed layer. 
(a)

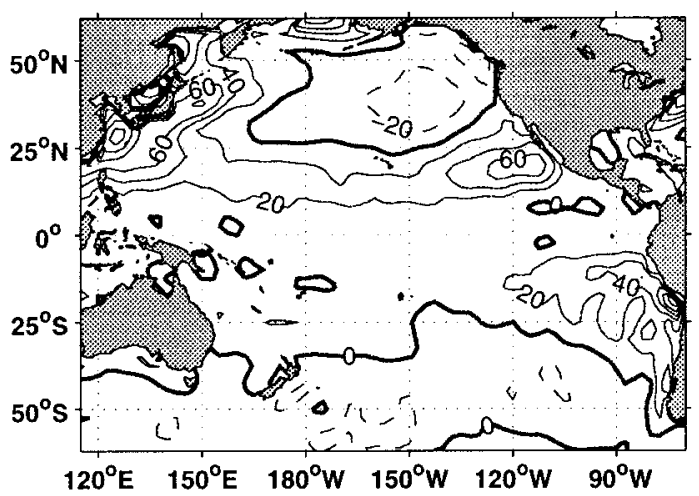

(b)

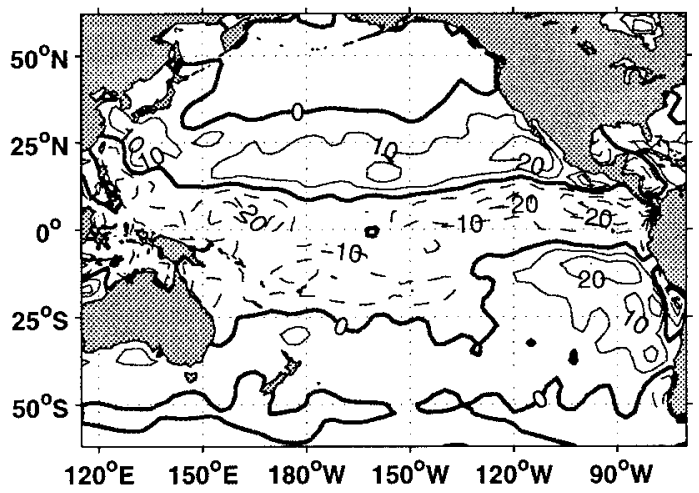

(c)

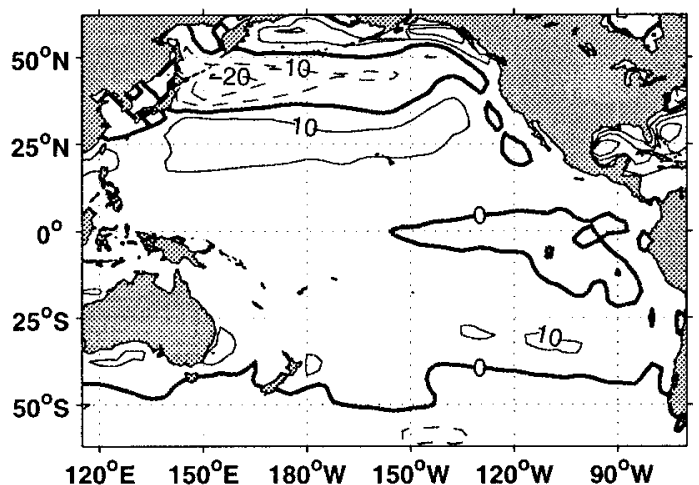

(d)

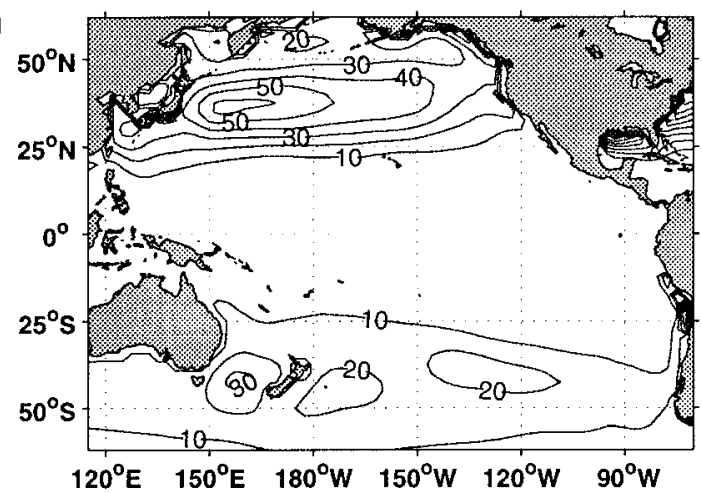

(e)

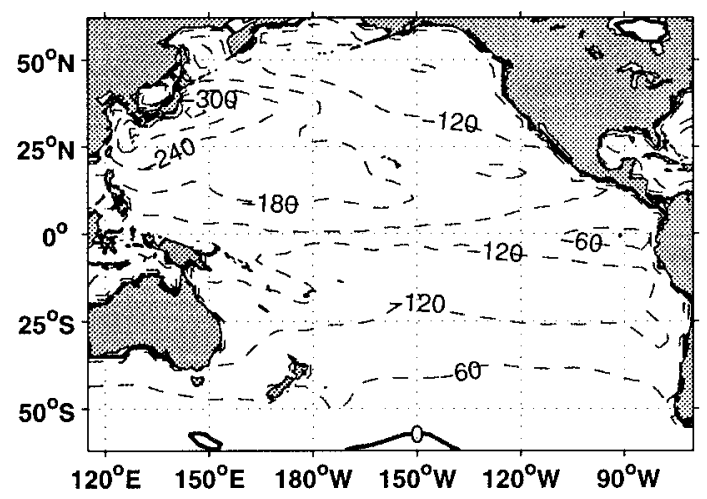

(f)

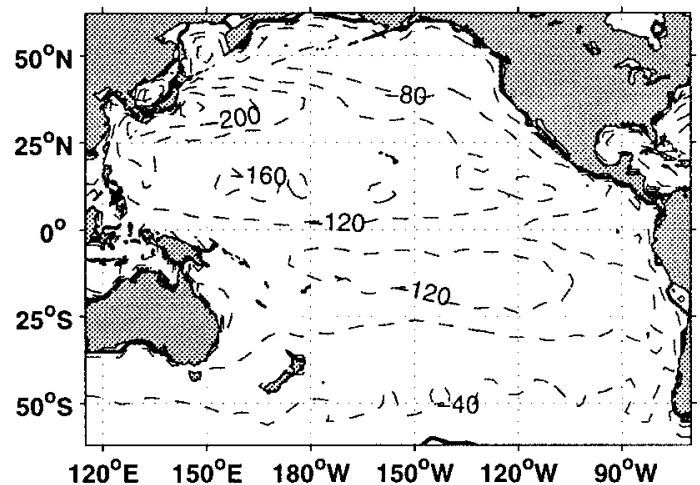

FIG. 1. Spatial distribution of the contribution to moist static energy budget in the surface layer [see Eq. (2)] in W m ${ }^{-2}$ (mean over Dec, Jan, Feb). (a) Horizontal advection, (b) subsidence, (c) horizontal eddy fluxes, (d) vertical eddy fluxes, (e) surface fluxes, (f) residual. All terms are plotted as if they were on the right-hand side of a moist static energy equation. The residual is the sum of the fields of (a)-(d).

\section{A parameterization of the impact of storms on the surface fluxes}

In the midlatitudes, baroclinic atmospheric eddies develop as available potential energy provided by the poleward and upward sloping isentropes is converted to kinetic energy. The transient eddies accomplish a net northward transport of heat and moisture as indicated by a cooling of the surface layer (Figs. 1c and 1d). Here we will use a model of the atmospheric mixed layer coupled to an ocean general circulation model to study the effect of the eddies on the upper ocean.

In our previous model of the atmospheric mixed layer the effect of eddies was neglected (e.g., Seager et al. 1995). This prompted us to seek a parameterization of the effect of the baroclinic eddies on the atmospheric mixed layer. In a study of eddy-induced circulation in the ocean, Gent and McWilliams (1990) showed that an additional advection of tracers arises from the correlation of the eddy components of layer thickness and ve- 
locity. This defines an eddy-induced transport velocity. Gent and McWilliams (1990) parameterized this eddy transport by a downgradient Fickian diffusion of isopycnal layer thickness. This mimics the baroclinic instability process. Here we use the same ideas to parameterize the eddies in the atmosphere. Kushner and Held (1998) have shown that this approach is applicable to the atmospheric eddies.

The impact of eddies on the atmospheric surface layer can be parameterized by adding an eddy-induced transfer velocity, $\mathbf{u}_{*}$ to the velocity $\mathbf{u}$; that is,

$$
\frac{1}{g} P\left(\mathbf{u}+\mathbf{u}_{*}\right) \cdot \nabla S-\frac{1}{g} \omega_{B}\left(S_{B}-S\right)=F .
$$

Here $F$ are the terms on the right-hand side of Eq. (2). An effective eddy-induced transfer velocity can be determined from the observed eddy fluxes of moist static energy in the lower atmosphere and the gradients of air temperature and humidity:

$$
\mathbf{u}_{*} \cdot \nabla S=\nabla \cdot \overline{\mathbf{u}^{\prime} S^{\prime}}-\overline{\omega^{\prime} S^{\prime}} / P .
$$

In order to diagnose $\mathbf{u}_{*}$ from the eddy flux divergences using Eq. (4) a long-term synoptic dataset is necessary. Here we use the NCEP-NCAR reanalysis data from 1958 to 1998 to determine $\mathbf{u}_{*}$. Monthly values of covariances in Eq. (4) and of the moist static energy at the surface are deduced from the data to construct monthly $\mathbf{u}_{*}$ fields. The covariances of the vertical velocity and moist static energy are determined from the 925-hPa surface, which is the second level in the NCEPNCAR reanalysis dataset. We chose to add the vertical eddy correlation term to the meridional eddy correlation term. This is reasonable since the $\overline{\omega^{\prime} S^{\prime}}$ term exchanges warm, moist low-level air on the equatorward side of the storm track with cool and higher dry air on the poleward side. The $\overline{v^{\prime} \omega^{\prime}}$ term at $925 \mathrm{hPa}$ is negative over most of the North Pacific in the winter; that is, anomalous southward transport is correlated with anomalous downward motion. This leads to cooling and drying of the surface air. This is analogous to a southward horizontal transport.

In Fig. 2 we show the diagnosed $\mathbf{u}_{*}$ in January and July. As expected, the amplitude is largest in the midlatitudes, where the isentropes slope upward and poleward associated with the midlatitude jet. Here the atmospheric eddies induce a cooling and drying, which is indicated by the equatorward directed vectors. The $\mathbf{u}_{*}$ forms into an elongated band stretching from the northeast of Japan to Alaska and from the southeast of Australia to Chile. It is remarkable that the spatial structure extends zonally over the entire Pacific. The observed flux divergences are higher at the western side of the basin than at the eastern side (Figs. 1c,d). The horizontal gradient of the mean moist static energy causes the $\mathbf{u}_{*}$ to extend more zonally than the eddy flux divergences themselves. However, as $\nabla S$ is smaller on the east side, the flux divergences on the east side of the basin are smaller than on the west side. In the North- ern Hemisphere summer $\mathbf{u}_{*}$ is greatly reduced. In the Southern Hemisphere, the reduction of $\mathbf{u}_{*}$ in the summer is less strong. This is clearly displayed in the seasonal variation of the zonally averaged $\mathbf{u}_{*}$ displayed in Fig. 3 . Note also that over the western boundary currents $\mathbf{u}_{*}$ is slightly smaller than over the open ocean. We will address this feature later in this paper.

In the next section we will specify the diagnosed eddy-induced transfer velocity in an atmospheric mixed layer model in order to validate the parameterization. In the atmospheric mixed layer model the surface heat fluxes are internally generated. Including the $\mathbf{u}_{*}$ will enhance the ocean-to-atmosphere surface fluxes and will tend to warm and moisten the surface boundary layer and cool of the sea surface temperature. Note that by using this procedure the position and strength of the storm track is fixed (except for seasonal variations). Low-frequency variability in the storm tracks is observed (Lau 1988). However, in this study we focus on the mean effect of the storms and a parameterization of that process on the atmospheric mixed layer. We do not study the impact of the storms on mechanical stirring and oceanic momentum fluxes. Model experiments with daily winds instead of monthly mean winds showed no big differences. Both model versions contained similar SST errors and indicate that cooling and drying by the storms need to be accounted for (see section 5). Note that by using daily winds the horizontal eddy fluxes were accounted for. Also the wind stresses included daily variations. However, the vertical eddy fluxes could not be accounted for as the vertical advection terms are parameterized in the atmospheric mixed layer model, which will be introduced in the next section. It appeared that this term especially needs to be properly parameterized. The dominance of the vertical eddy fluxes of moist static energy compared to the horizontal eddy fluxes was already noted in section 2 (see Figs. 1c,d).

A successful representation of the cooling by storms can be used to study the effect of the storm track on air-sea interaction and the oceanic state. An atmospheric mixed layer model coupled to an ocean model will be run with and without the additional eddy-induced transfer velocity to study the impact of the storm track. The models are described in the next section.

\section{Experimental setup}

\section{a. The atmospheric mixed layer model}

The atmospheric mixed layer (AML) model used in this study simulates either a dry convective layer or a subcloud marine boundary layer of a thickness of 60 $\mathrm{hPa}$. The model is described by Seager et al. (1995) and has been used extensively for tropical studies. In the AML the virtual potential temperature and the specific humidity are computed from a balance of advection, surface fluxes, fluxes at the top of the mixed layer, and radiative fluxes. The surface fluxes are determined by 


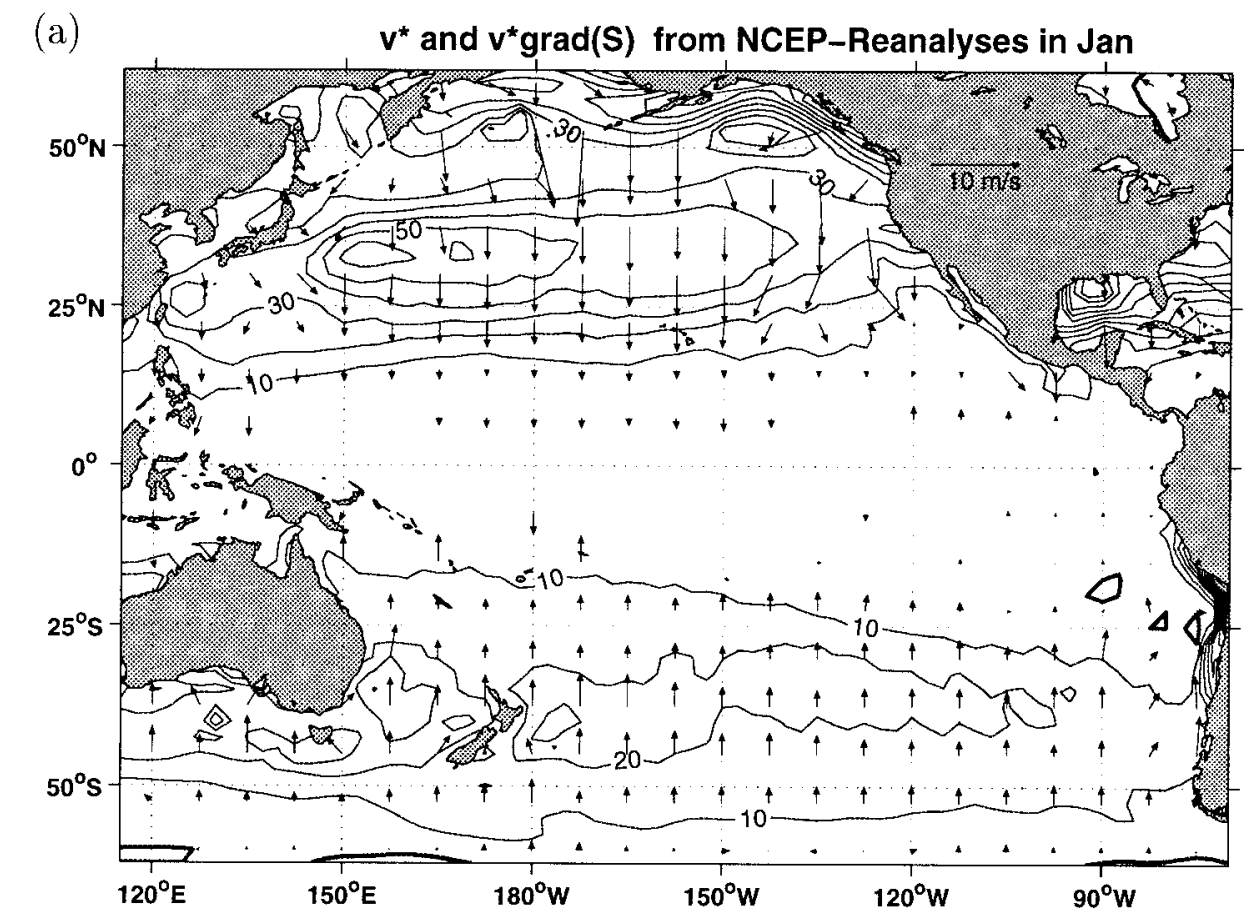

(b)

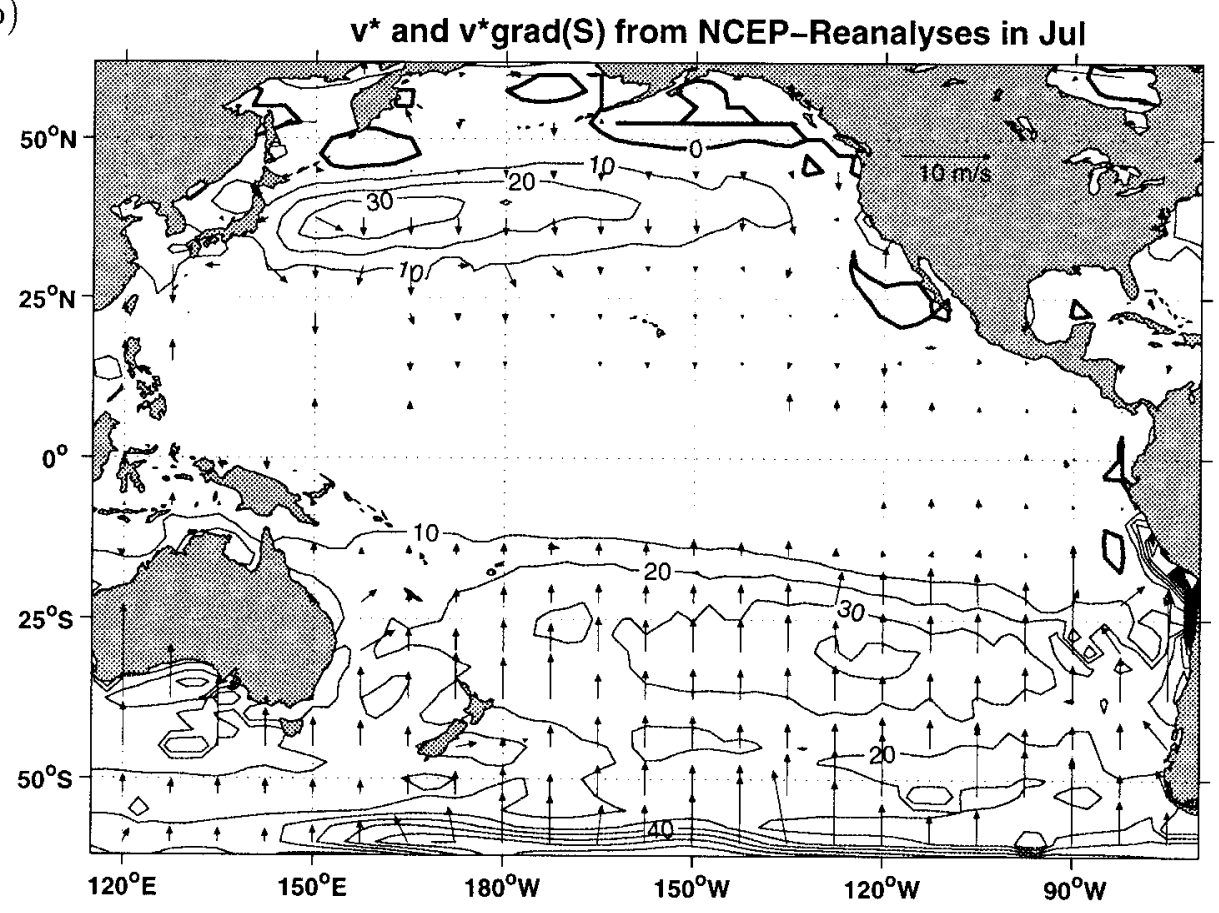

FIG. 2. The eddy induced transfer velocity in (a) Jan and (b) Jul, derived from the NCEP-NCAR reanalyses data. Transport of moist static energy by the eddy-induced velocities (in $\mathrm{W} \mathrm{m}^{-2}$ ) is contoured.

familiar bulk transfer formulae. The fluxes at the top are parameterized according to Seager et al. (1995). For the exact formulation of the model and the parameters therein, we refer to Seager et al. (1995) and Seager et al. (2000). In the AML the surface latent and sensible heat and longwave radiative fluxes can evolve freely and air temperature and humidity variations are internally computed.

The AML is forced by monthly mean wind speed and vector wind fields from the NCEP-NCAR reanalysis 


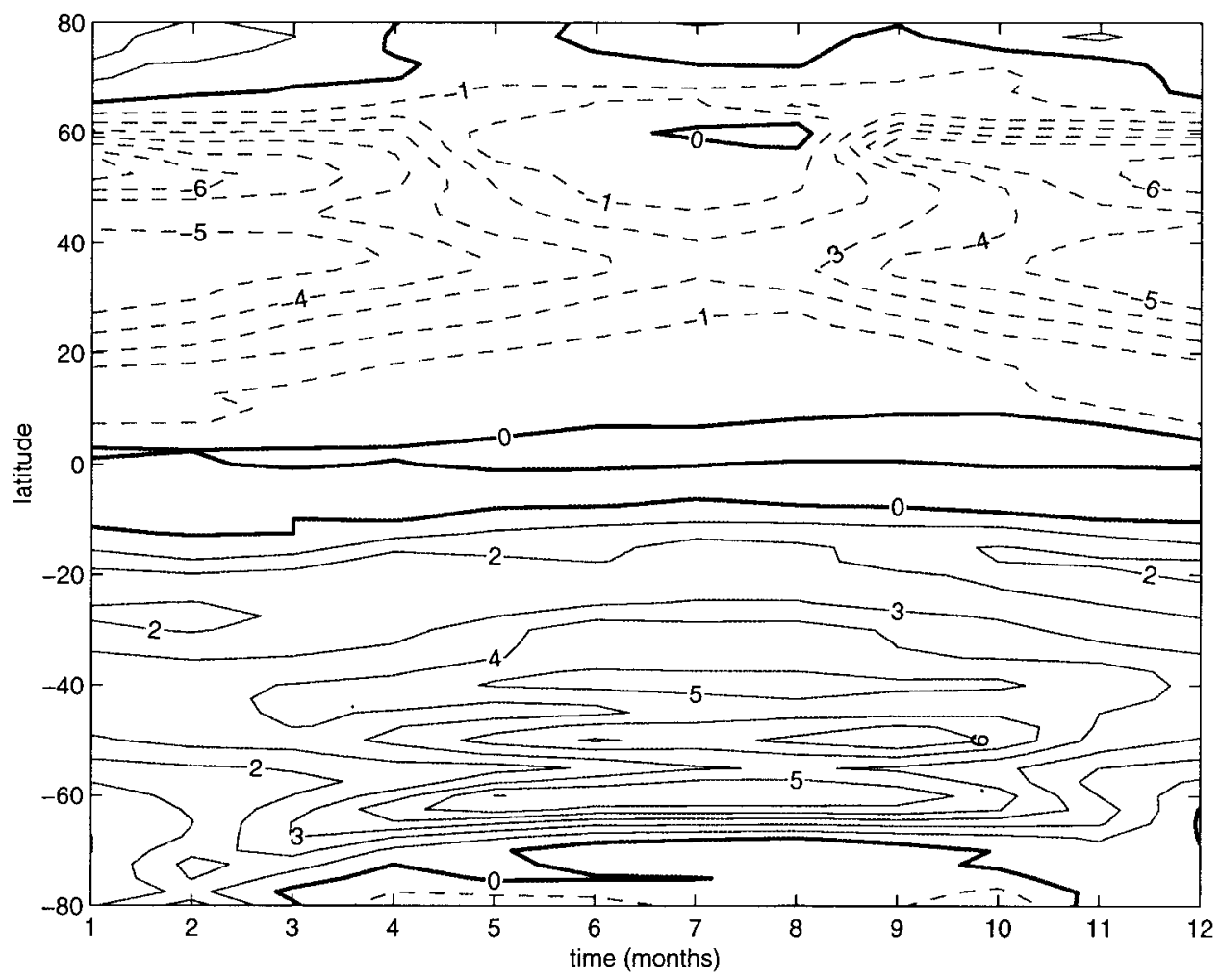

FIG. 3. Seasonal variation of the meridional component of the eddy-induced transfer velocity $\left(\mathbf{u}_{*}\right)$ averaged between $180^{\circ}$ and $140^{\circ} \mathrm{W}\left(\mathrm{m} \mathrm{s}^{-1}\right)$.

data. Furthermore fractional cloudiness and the solar radiation at the sea surface is prescribed (ISCCP, Bishop and Rossow 1991). At the lateral boundaries the potential temperature and the specific humidity are prescribed (NCEP-NCAR reanalysis). When the model is not coupled to the ocean, the SST is prescribed according to Levitus and Boyer (1994).

The model domain consists of the Pacific basin reaching from $62^{\circ} \mathrm{N}$ to $62^{\circ} \mathrm{S}, 90^{\circ} \mathrm{E}$ to $80^{\circ} \mathrm{W}$. Away from the equator, the horizontal resolution is $2.5^{\circ}$ in the meridional and zonal directions. In the Tropics the meridional resolution is increased to $0.5^{\circ}$. This resolution is based on that of the ocean model, which has been chosen to better resolve the critical scales of the equatorial waveguide.

A novelty compared to previous versions of the AML model is the inclusion of a parameterization of the impact of the storms on the heat budget according to Eq. 4. In earlier versions of the model (e.g., Visbeck et al. 1998) the eddy-induced transfer velocity was parameterized in terms of gradients of surface air temperature. In that model version the strength and position of the storm track was not constrained. The parameterization appeared not to represent the eddies very well. Also, using daily winds did not improve the storm-track-driven heat flux. Therefore, in the present study, we chose to specify the eddy-induced velocity derived from the reanalysis data. We ran the AML for 10 years with pre- scribed SST to validate the parameterization. Figures $4 a, b$ show how the simulated eddy flux divergences of moist static energy [left-hand side of Eq. (4)] compare to the observed eddy flux divergences from the NCEPNCAR reanalysis data [right-hand side of Eq. (4)]. Note that the moist static energy gradients are internally generated by the AML. Over most of the basin the difference between simulated and observed eddy flux divergences is less than $10 \mathrm{~W} \mathrm{~m}^{-2}$. As the amplitude of the difference is at least five times smaller than that of the flux divergence itself (Figs. 1c,d), the parameterization can be considered successful. Significant differences are only found close to the southern boundary in July. As the parameterization represents the eddy fluxes well, simulations with and without the eddy-induced transfer velocity can be used to study the effect of the storm tracks on the heat fluxes and the oceanic state (see section 5).

\section{b. The dynamic ocean model}

The numerical ocean model is a primitive equation $z$-coordinate model that originates from the Gent and Cane model (see Visbeck et al. 1998; Rodgers et al. 1999). Among the main differences compared to the reduced-gravity Gent and Cane model is the inclusion of a barotropic solver according to Naik et al. (1995) together with a realistic bathymetry. Also, the model 


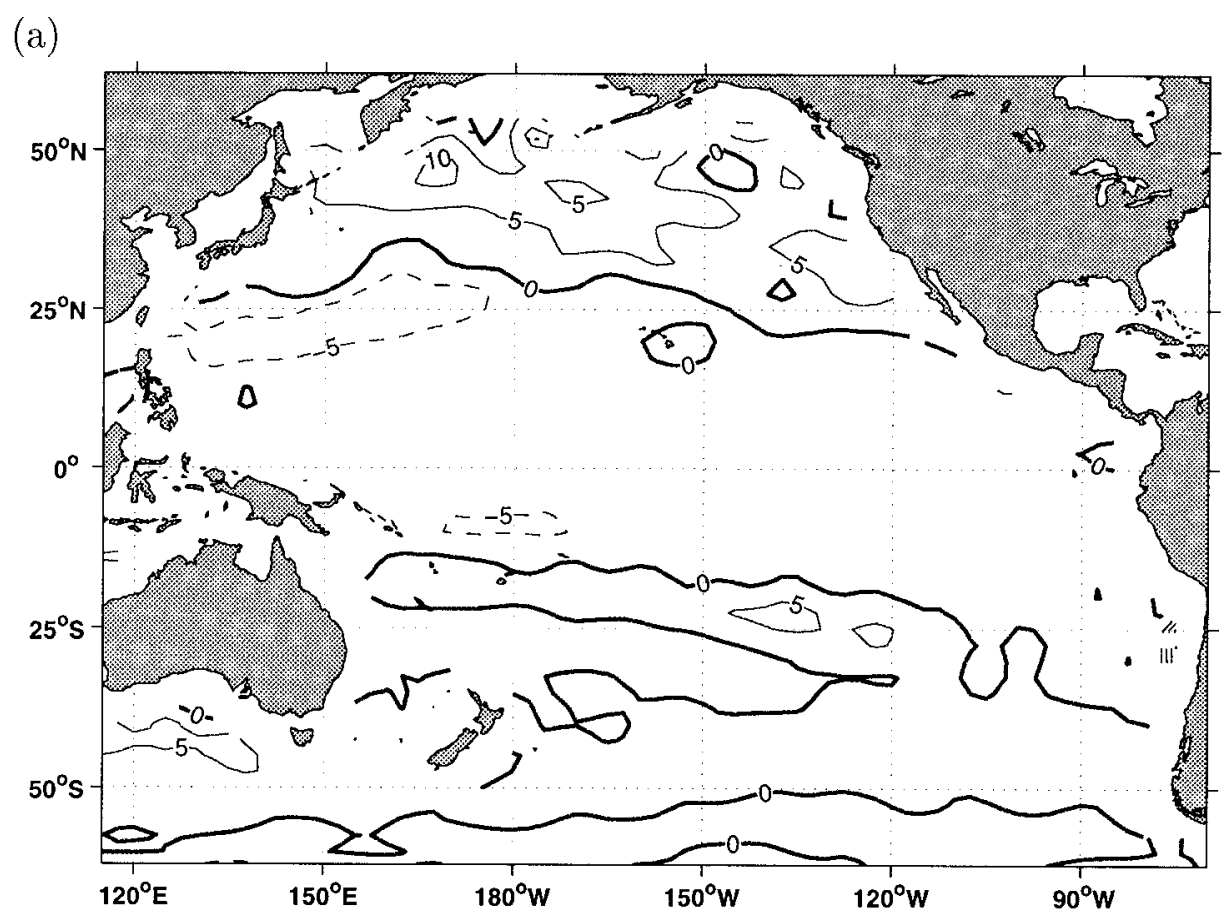

(b)

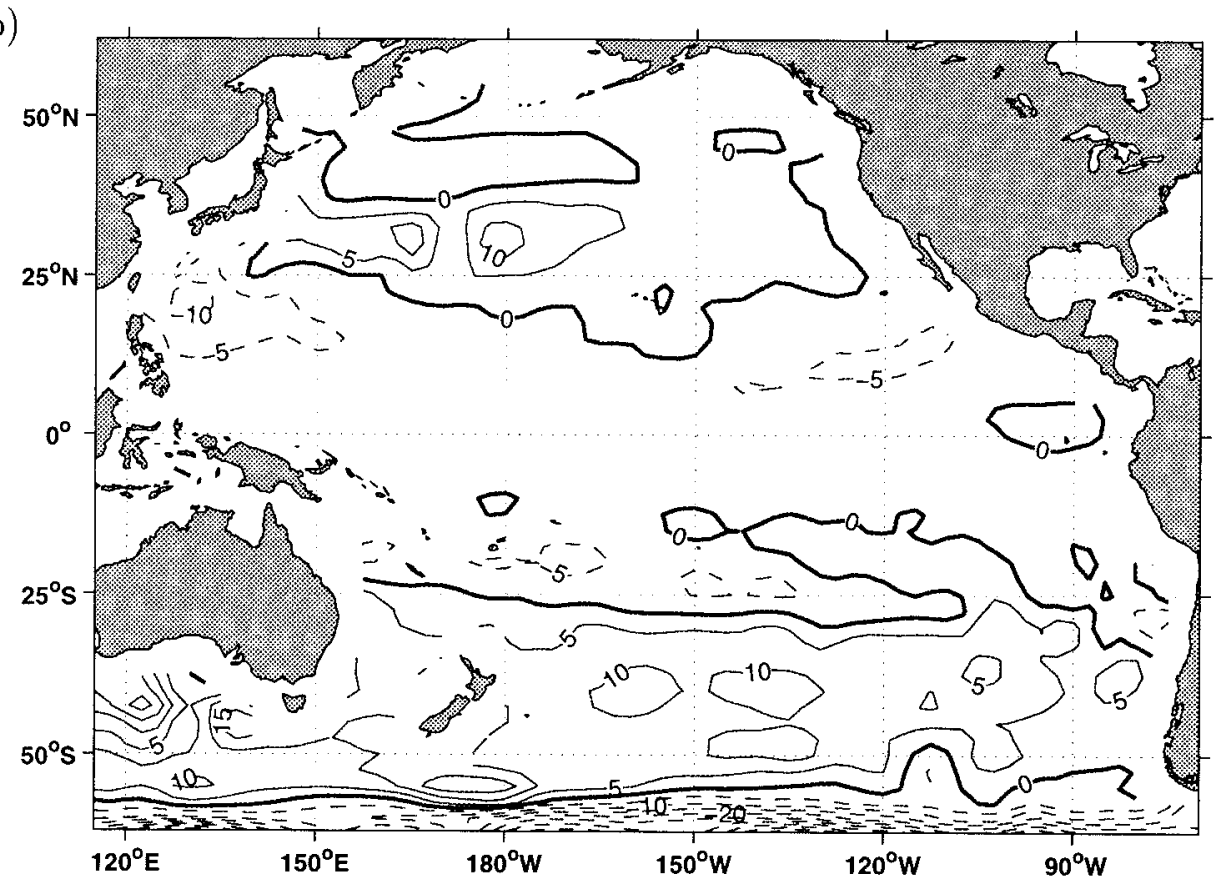

FIG. 4. Difference between observed (NCEP-NCAR reanalyses) and modeled eddy induced transport of moist static energy $\left(\mathbf{u}_{*} \nabla S\right)$ in the atmospheric mixed layer $\left(\right.$ in $\left.\mathrm{W} \mathrm{m}^{-2}\right)$.

includes a Kraus-Turner surface mixed layer parameterization and a simple 11/2-layer thermodynamic ice model now. The Gent and McWilliams (1990) eddy parameterization is implemented with spatially varying diffusivity according to Visbeck et al. (1997). The vertical mixing is Richardson number dependent. The mod- el uses a Total Variation Diminishing scheme for the horizontal advection terms. For the time differencing a second-order Lorenz $\mathrm{N}$-cycle is used. The model has 20 layers in the vertical, of which 10 are in the upper 1000 $\mathrm{m}$. The horizontal resolution corresponds to that of the AML model. At the southern edge of the domain the 
temperature and salinity are restored to observed values from Levitus and Boyer (1994) and Levitus et al. (1994). The barotropic transport at the Indonesian Throughflow is set to a value of $10 \mathrm{~Sv}\left(\mathrm{~Sv} \equiv 10^{6} \mathrm{~m}^{3} \mathrm{~s}^{-1}\right)$. The ocean model is coupled to the AML model to create the socalled LOAM model.

\section{The impact of midlatitude storm track on surface heat fluxes, SST, and thermocline}

\section{a. Impact on surface heat fluxes}

As shown in section $4 \mathrm{a}$, the effect of storm tracks can be successfully represented by an eddy-induced transfer velocity derived from observed eddy flux divergences and gradients of moist static energy. So, to study the impact of the storms on the surface heat fluxes, the AML model (SST prescribed) can be run with and without the additional eddy-induced transfer velocity. Figure 5 a shows the difference between the latent and sensible heat fluxes in both runs after 10 years. Clearly, the eddies provide an extra monthly mean cooling of up to $60 \mathrm{~W} \mathrm{~m}^{-2}$ in the midlatitudes. The broad region of cooling is consistent with the pattern of the eddy transfer velocity (Fig. 2). Note that the maximum cooling occurs far offshore. In earlier versions of the model (e.g., Visbeck et al. 1998; Seager et al. 2000) the $\mathbf{u}_{*}$ has been related to the simulated surface air temperature. This resulted in large eddy fluxes close to the coast on the western side of the basin where the mean meridional temperature gradients are large. However, as shown by Swanson and Pierrehumbert (1997) the effective eddy diffusivity in the Pacific storm tracks (diagnosed from NCEP data) increases toward the east as storms develop, consistent with a maximum impact of the eddies offshore. Pure isobaric mixing along a mean temperature gradient, on which the parameterization in previous model versions was based, would result in unrealistically small mixing lengths and damping times. The reason for the failure of the local mixing parameterizaton could be due to the fact that mixing occurs along isentropes instead of isobars or to strong thermal interaction with the underlying oceanic surface. The latter process can maintain the strong meridional temperature gradient against dissipation by damping the air temperature fluctuations. This effect should be stronger in regions of deep mixed layers (large heat capacity), that is, just south of the Kuroshio close to the Japanese coast.

Although cooling is substantial, it is not enough to remove all errors in the surface heat fluxes in the model. Figure $5 \mathrm{~b}$ shows the difference between the latent and sensible heat fluxes in the AML model and the NCEPNCAR reanalysis dataset. Away from the midlatitudes, the errors are less than $20 \mathrm{~W} \mathrm{~m}^{-2}$. Considering the uncertainties in the data, this is acceptably small. However, large errors in the Kuroshio region remain. In winter the outgoing heat fluxes are about $25 \%$ too low, although the annually averaged error is only $30 \mathrm{~W} \mathrm{~m}^{-2}$ in this region. As the effect of the eddies are well represented (Fig. 4), these errors must be due to another physical process or due to uncertainties in the data. To explore the latter possibility, we performed a run with the AML model using input fields from a coupled atmospheric general circulation (Geophysical Fluid Dynamics Laboratory) mixed layer model. (i.e., the SST and the winds from the coupled model are specified; M. Alexander 1999, personal communication). The fluxes produced by the AML model are compared with those from the coupled model. The advantage of this setup is that the surface fluxes from the coupled model are consistent with the input fields of the AML. In this case the data is "perfect," that is, all fields are consistent with each other. The errors in the simulated heat fluxes were virtually the same. Apparently, the AML misses an essential process in the western boundary current region. This confirms the results of the budget analysis of the surface layer described in section 2 . The residual diagnosed in section 2 is balanced by entrainment and radiative cooling (see Seager et al. 1995). When the parameterizations for radiation and entrainment used in the AML model were applied to the observed fields in order to close the budget, a residual still remained. This residual appeared to have the same pattern and amplitude as seen in Fig. 5. This means that all terms are modeled correctly except for the entrainment closure (radiative cooling is uniform and smaller). As the boundary layer air advects offshore a deep cloud layer forms above the well-mixed subcloud layer (e.g., Grossman and Betts 1990) as a result of powerful shallow convection. This convection, possibly augmented by deep frontal convection, acts to bring dry air down from above and increases the surface fluxes. This process is not well accounted for in the AML model. However, the goal of this study is to investigate the impact of the storm tracks on the ocean. It is clear that the present setup is suitable for this in that storm tracks are well represented. The effect of the storms on the surface fluxes has been shown to be substantial. Their impact on the oceanic state is discussed in the next section.

\section{b. Impact on SST}

The SST is determined by oceanic heat advection, mixing, and surface heat fluxes. As shown in the previous sections, storms act to increase the outgoing surface heat fluxes. The ocean model coupled to the AML has been run for 20 years with and without the parameterization of the effect of storms on the surface fluxes to estimate the impact of this increased cooling on SST. In Fig. 6a we show the difference between the SSTs in January in both runs. As expected, the effect is largest in the midlatitudes. The impact of the storms is to cool the SST by at least $3 \mathrm{~K}$. The cooling is larger in the eastern side of the basin because the mixed layer is shallower there. Figure $6 \mathrm{~b}$ shows the difference between SST from the NCEP-NCAR reanalysis data and 


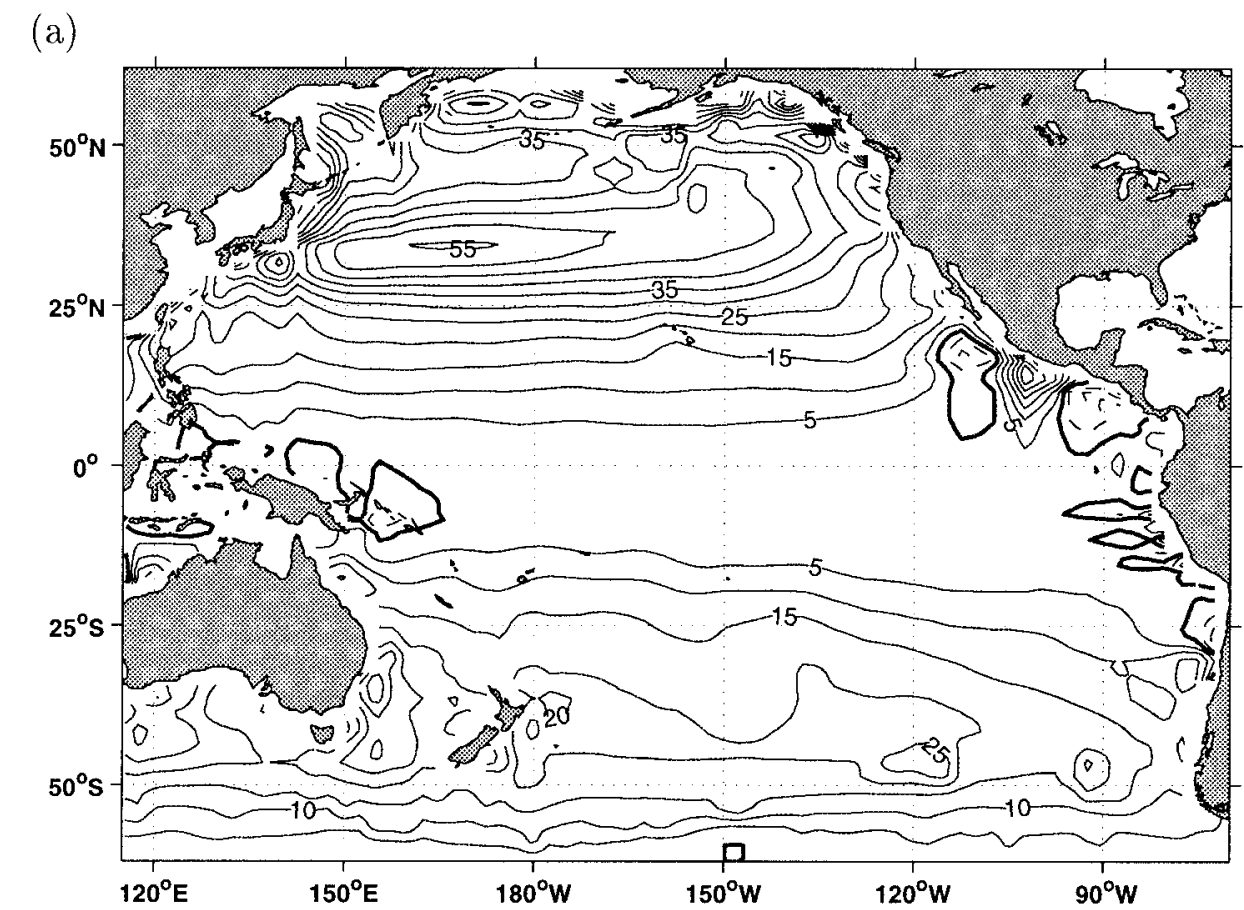

(b)

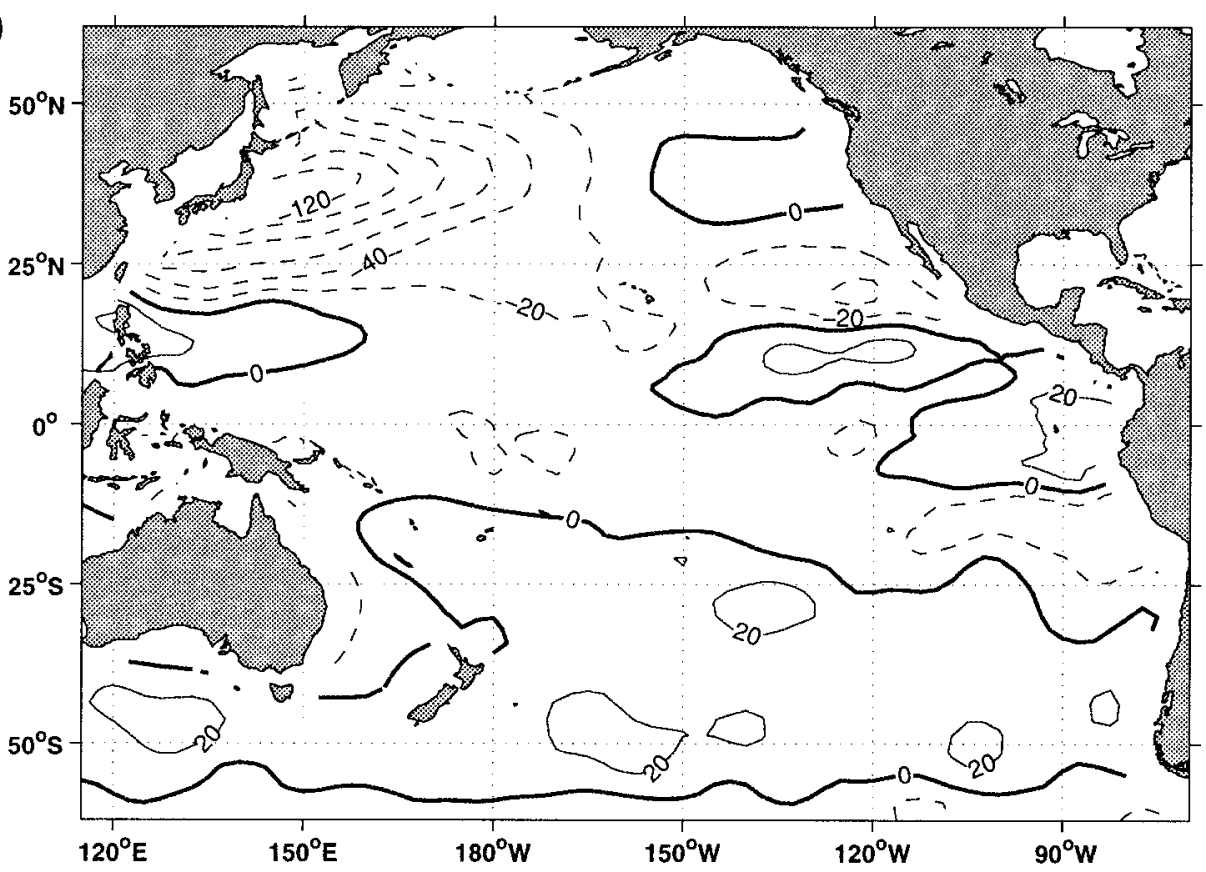

FIG. 5. (a) Difference between latent plus sensible heat fluxes $\left(\mathrm{W} \mathrm{m}^{-2}\right)$ with and without parameterization of additional cooling due to storms in January. (b) Difference between observed (NCEP-NCAR reanalysis) and modeled (AML) sensible plus latent heat fluxes in Jan $\left(\mathrm{W} \mathrm{m}^{-2}\right)$.

the modeled SST in the model including the storm tracks. The error in SST is generally small. Without the eddy-induced transfer velocity the SST was too high in almost the entire basin. SST was up to $4 \mathrm{~K}$ too warm in the Northern Hemisphere winter in the $\mathrm{Ku}-$ roshio extension. Now the error is generally smaller than $1 \mathrm{~K}$. The error in the South Pacific has also been reduced significantly.

Between $150^{\circ} \mathrm{E}$ and $180^{\circ}$ along $40^{\circ} \mathrm{N}$ the simulated SSTs are too high. This is likely associated with the too 

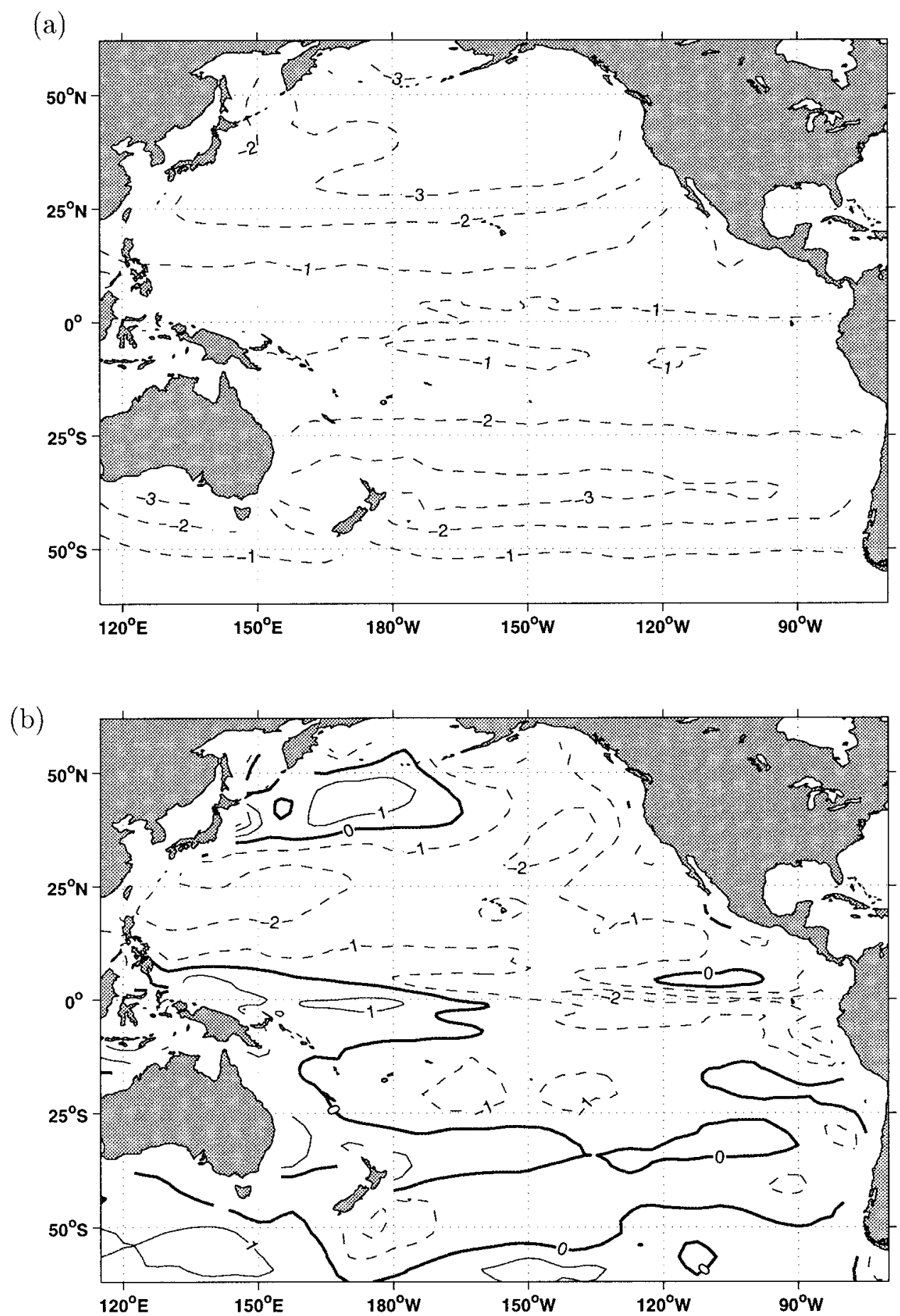

FIG. 6. (a) Difference between SST (K) in the LOAM model with and without parameterization of additional cooling due to storms in Jan. (b) Difference between observed (NCEP) and modeled (LOAM) SST in Jan. (c, d) Same as (a, b) but for Jul.

small outgoing heat fluxes produced by AML in this region (see Fig. 5b). The SSTs are somewhat too low along $15^{\circ}-25^{\circ} \mathrm{N}$. This may be caused by relatively high wind speeds in this region in the NCEP-NCAR reanalysis data. Another area where the error is relatively large is the eastern tropical Pacific. Here the error is most likely caused by errors in the upwelling due to surfacing of the undercurrent, a general flaw of ocean models with relatively coarse vertical resolution. Increasing the number of layers in the upper thermocline 


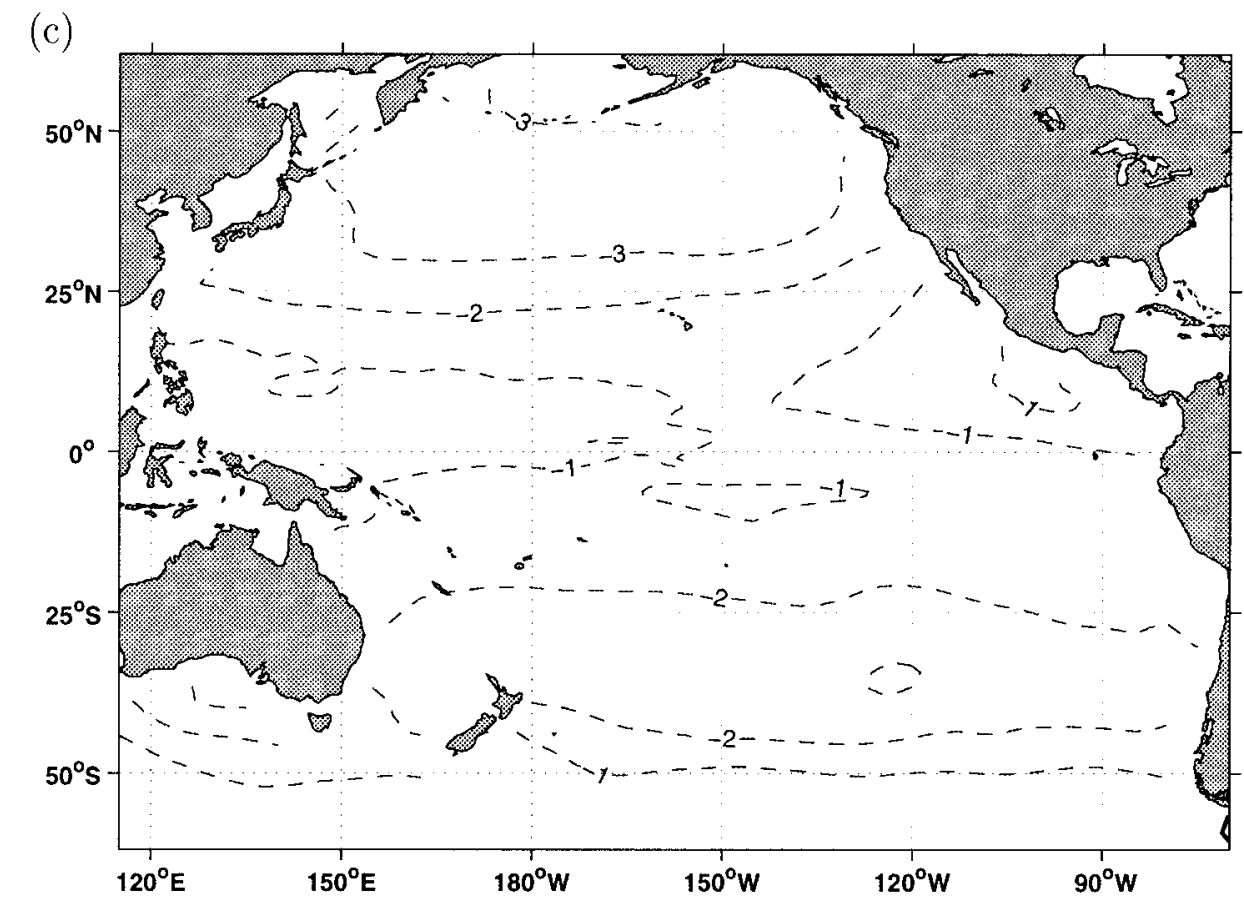

(d)

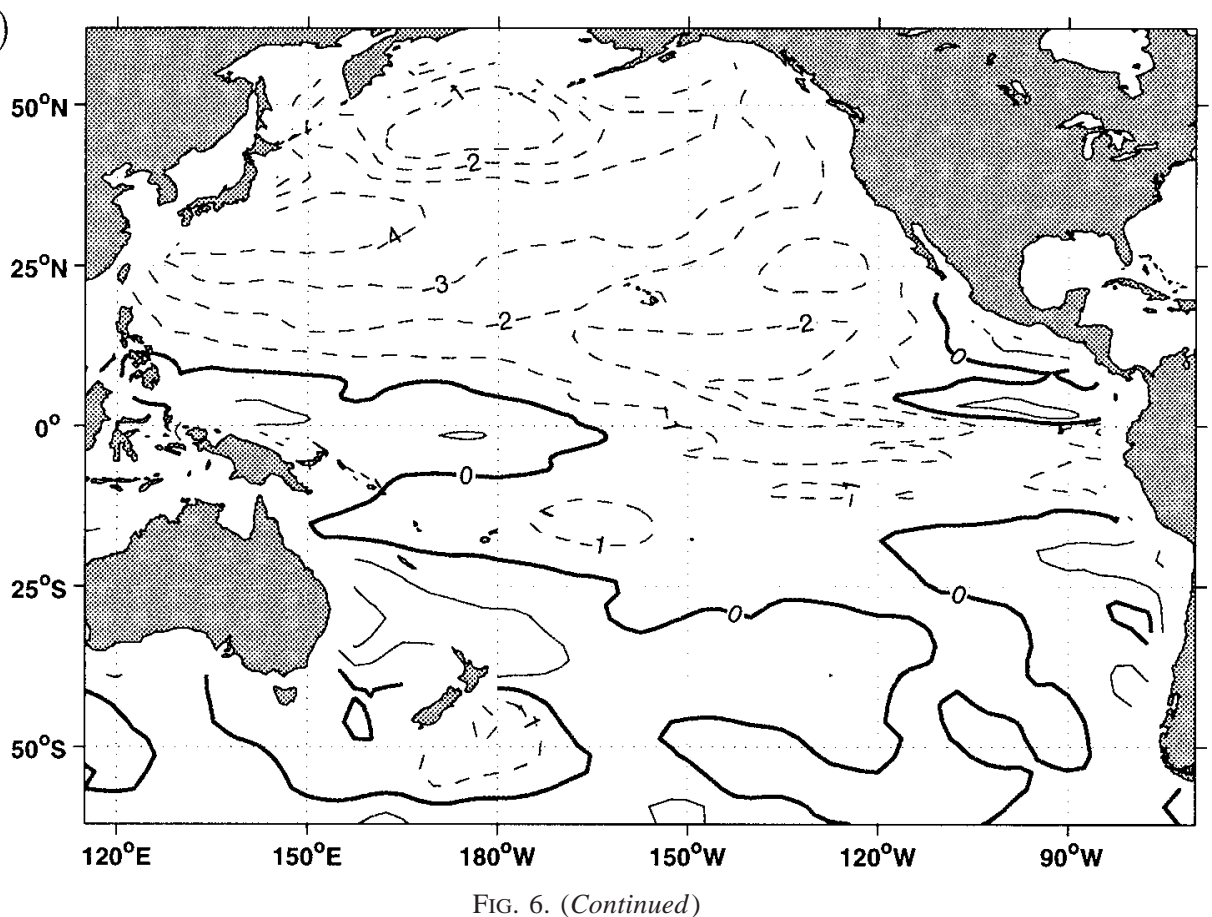

will reduce the error (e.g., Murtugudde et al. 1996). The change of SST in the Tropics due to the storms is remarkable since the eddy-induced transfer velocity is almost zero in this region. As the change cannot be locally forced, a change in ocean dynamics is implicated. A likely explanation is that changes in the subtropical meridional overturning cell, which has a downward branch at about $30^{\circ} \mathrm{N}$ and upwells near the equator, influences the tropical SST (see section 5c). The presence of such cells have been shown in models and data (e.g., Rothstein et al. 1998; Johnson and McPhaden 1999). Additionally, cooler midlatitude air is advected into the tropical regions.

The effect of the parameterization is similar in the 
austral winter as in boreal winter (Fig. 6c). Storms act to cool almost the entire Pacific by as much as $3 \mathrm{~K}$. Figure $6 \mathrm{~d}$ shows that in austral winter the simulation of SST is excellent in the South Pacific when the parameterization of cooling by the storms is included. In the North Pacific, however, the cooling appears to be too large, although the error is reduced. The too strong cooling is not merely caused by the storms. As mentioned before, the NCEP-NCAR reanalysis wind speed in the model simulation has been enhanced by a factor 1.25. This was motivated by the low NCEP-NCAR reanalysis wind speeds compared to European Centre for Medium Range Weather Forecasts reanalysis and COADS winds. The correction led to better simulated SSTs in the central North Pacific, but it has led to too much cooling in some other regions.

It is clear that the storms cool the SST significantly in the midlatitudes. In general the SST is much better simulated when the cooling by the storm tracks is included. During the winter season especially, SST errors are greatly reduced. The cooler SSTs and increased outgoing heat fluxes affect the water mass transformation, the mixed layer depth and the characteristics of the subducted water masses. This will be investigated in the next section.

\section{c. Impact on the thermocline}

Horizontal variations in the buoyancy fluxes induce horizontal gradients in the mixed layer depth. Since the amount of subducted water is significantly influenced by lateral flow through the sloping winter mixed layer base, the buoyancy fluxes strongly influence subduction (Woods 1985). In addition, both the SST and sea surface salinity are modified by heat and freshwater fluxes. Thus the amount and the characteristics of the subducted water, and therefore the stratification, are strongly influenced by the surface buoyancy fluxes. As shown in the previous sections, storms enhance outgoing surface heat fluxes over the midlatitude Pacific. In the following, we investigate the impact of the storms on the interior of the ocean by studying transformation rates of water at the surface, the influence of storms on mixed layer depth, as well as effects on subsurface properties as revealed by cross-section plots.

\section{1) IMPACT ON WATER MASS TRANSFORMATION}

Buoyancy fluxes cause water to change its density. The rate at which water is transformed from one density to another by buoyancy fluxes can be determined from the surface distribution of the surface fluxes (Walin 1982; Speer and Tzipermann 1992):

$$
f(\sigma)=\frac{\alpha}{\rho c_{p}} Q_{\text {net }}-\beta S \frac{(E-P)}{(1-S / 1000)} .
$$

Here $Q_{\text {net }}$ is the net surface heat flux, $E-P$ the freshwater flux, $S$ the salinity, and $\alpha$ and $\beta$ the thermal and haline expansion coefficients. The total transformation per density class $(\delta \rho)$ can be obtained by integrating the transformation rates over the area $(A)$ of the surface outcrop of water in that density class:

$$
F(\sigma)=\frac{1}{\delta \rho} \int f(\sigma) d A(\sigma) .
$$

The divergence of the transformation (in density space) is the formation of a water mass. Over the Pacific Ocean basin, the net formation of water masses must be balanced by either an inflow or an outflow of a water mass at the boundaries. Additionally, the diffusive mixing in the mixed layer and in the interior contributes to the transformation of water masses. However this plays a minor role in water mass transformation rates in the midlatitudes (Nurser et al. 1999; Marshall et al. 1999).

An interesting and useful diagnostic is the total diapycnal transfer by surface fluxes through surface outcrops south (or north) of a latitude $\Theta$ (see Marsh et al. 2000, hereafter MNMN). This represents an overturning streamfunction in density coordinates if the convergence of the interior diapycnal density flux is zero and if the volume at densities lower than $\sigma$ is not inflating or deflating (see MNMN for details); that is,

$$
\psi(\sigma, \theta)=\int_{\theta_{\max }}^{\theta} F d \theta .
$$

Here $\psi(\sigma, \theta)=\int_{x: \theta(x)=\Theta} \int_{\rho}^{\rho_{\max }} h v d \rho d l$. This is the total transport of water denser than $\rho$ across the line of latitude $\theta=\Theta$, where $\rho_{\max }$ is the maximum density at that latitude. Here, we will use these relations to show the impact of the storm tracks on the heat fluxes, and hence on the meridional overturning streamfunction.

In Fig. 7 the annual mean meridional transformation streamfunction is presented according to Eq. (7). Positive values indicate a diapycnal volume flux toward higher densities. For reference, the potential density at the surface is shown in Fig. 8. The model shows a maximum flux toward higher densities at around $\sigma=$ $23 \mathrm{~kg} \mathrm{~m}^{-3}$ in the North Pacific. This transport is around $28 \mathrm{~Sv}$, and is in excellent agreement with observations. Almost $50 \%$ of the strength of the shallow overturning in the midlatitude North Pacific is generated by the cooling due to the storms (see Fig. 7b). The downward branch of this positive cell is located at $\sigma=25.5 \mathrm{~kg}$ $\mathrm{m}^{-3}$ in the model. The outcrop of this isopycnal is just south of the Kuroshio Extension. At this latitude, the subtropical and central mode waters are formed (Suga and Hanawa 1995). Indeed, the core of these homogeneneous subsurface water masses is found at $\sigma=$ $25.5 \mathrm{~kg} \mathrm{~m}^{-3}$. It is clear that the storms contribute greatly to the formation of these mode waters, which dominate the stratification of the upper North Pacific.

In the model, there is too much transport toward lower densities in the tropical regions (around $\sigma=21.5 \mathrm{~kg}$ $\mathrm{m}^{-3}$ ). Storms act to reduce the strength of this tropical overturning cell by as much as $30 \mathrm{~Sv}$, but this is still 
(a)
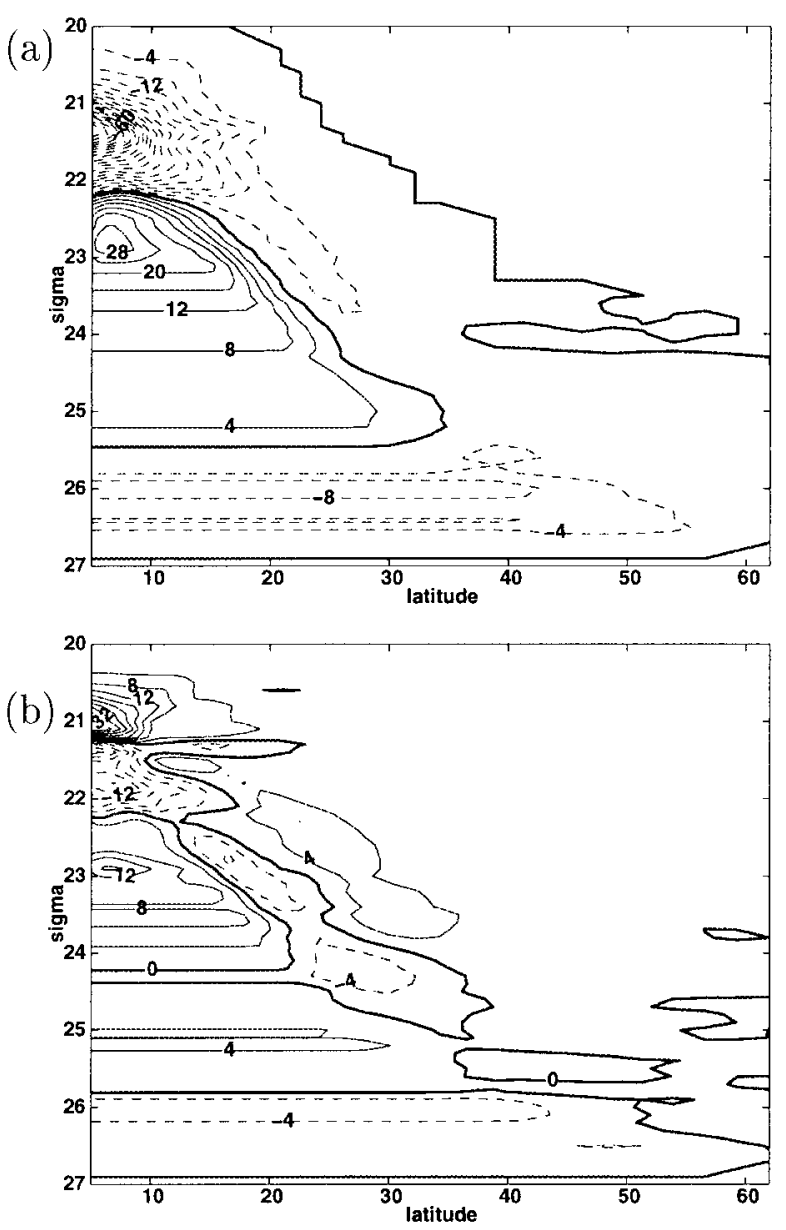

(c)

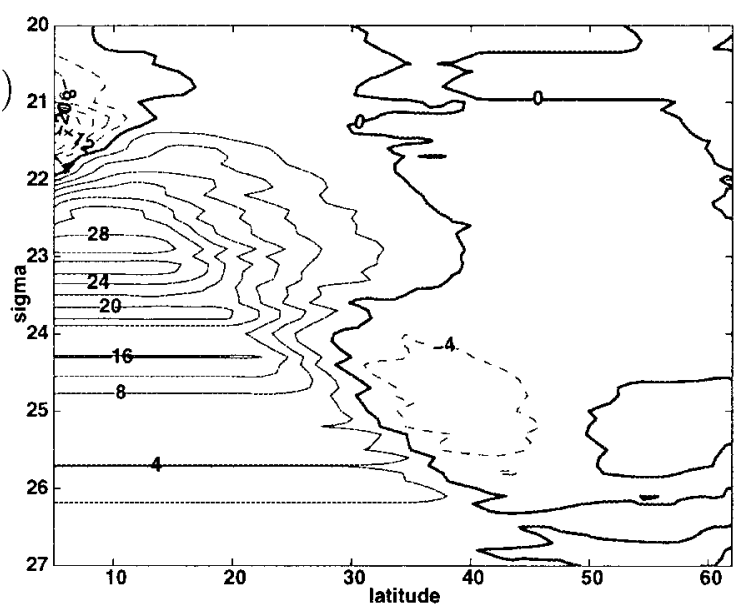

(d)

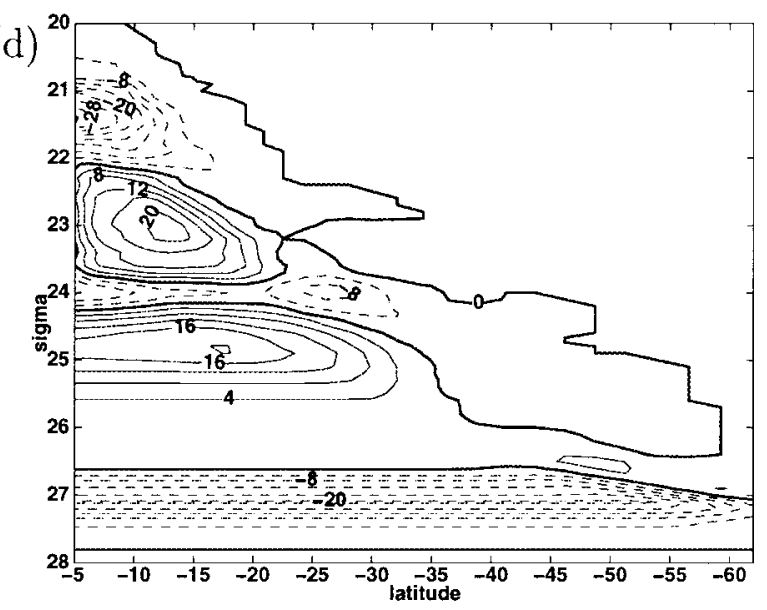

(e)

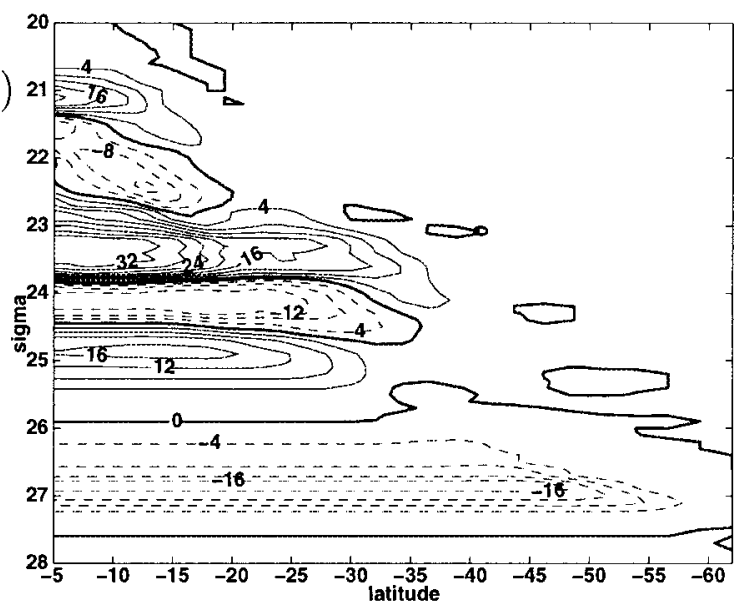

(f)

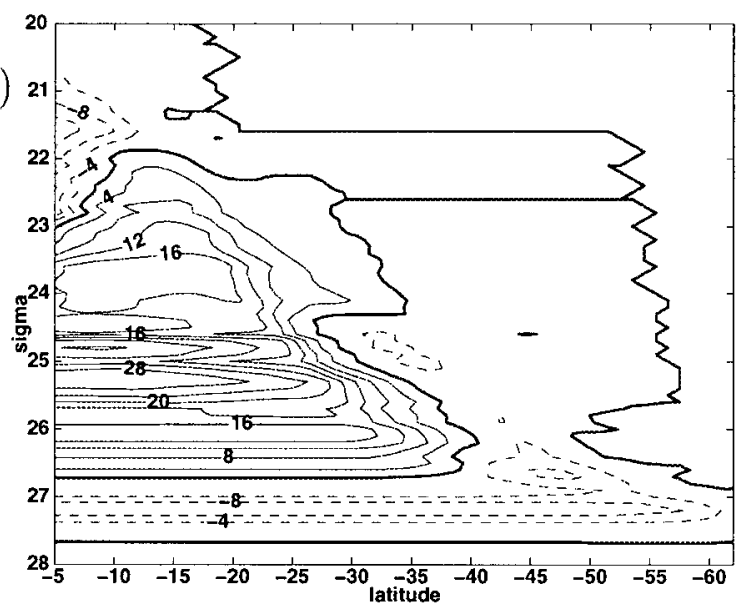

FIG. 7. Annually averaged transformation streamfunction (Sv). (a) Model (LOAM) with parameterization of additional cooling due to storms, (b) difference between model (LOAM) with and without the parameterization, and (c) according to NCEP buoyancy fluxes and Levitus SST and SSS in the North Pacific. (d), (e), (f) As in (a), (b), and (c) but for the South Pacific.

not enough. The main reason for the too low values in the tropical region is that the area covered by water of $\sigma \approx 21 \mathrm{~kg} \mathrm{~m}^{-3}$ is lower in the model compared to the observations. As shown in Fig. 5a the heat fluxes in the Tropics are close to observations. Nevertheless, the im- pact of the storms on the Tropics is remarkable. As $\mathbf{u}_{*}$ is small in this region, the impact is indirect. Apparently a change in the shallow meridional overturning cells in the ocean is induced by the $\mathbf{u}_{*}$ (see Fig. 7b). Changes in the downwelling branches of the overturning are ex- 


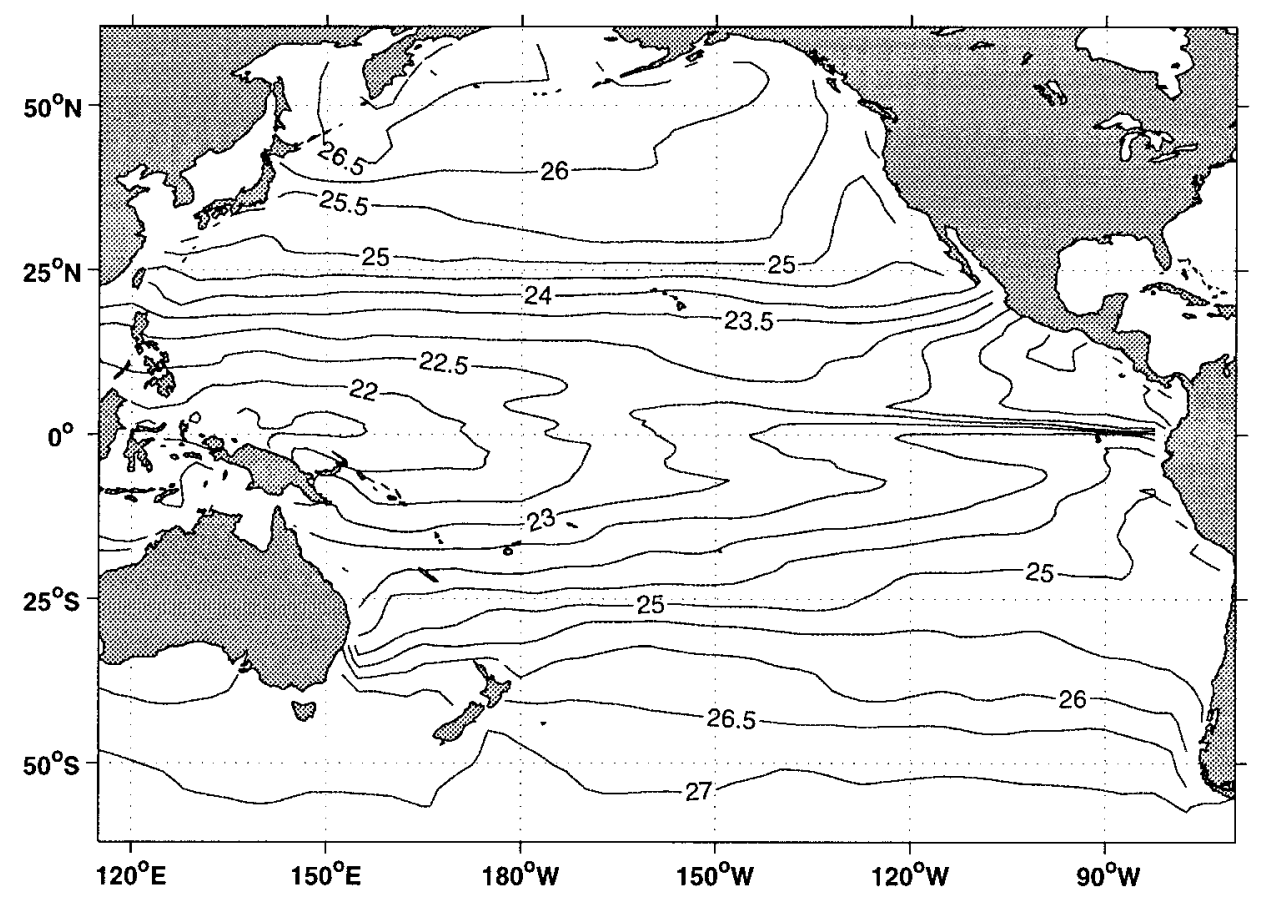

FIG. 8. Maximum potential density at the surface $\left(\mathrm{kg} \mathrm{m}^{-3}\right)$.

pected to induce changes in the upwelling branches as well, as interior mixing is small away from the Tropics. However, we should be careful, as vertical mixing is expected to contribute significantly to the overturning in the Tropics (Nurser et al. 1999). In the present analysis the role of vertical mixing could not be included. That the overturning is too strong at low latitudes may be due to errors in the heat fluxes in the eastern Pacific. Here the undercurrent surfaces, resulting in SSTs that are too low. In response, there is too much warming, as revealed by the heat fluxes. As stated before, an increase in the number of layers in the ocean model may resolve some of the problems.

The lightening of surface waters around $\sigma=26 \mathrm{~kg}$ $\mathrm{m}^{-3}$ is absent in the observations and seems to be enhanced by the storms in the model. The storms act to heat in the summer in a small region around $45^{\circ} \mathrm{N}, 160^{\circ} \mathrm{E}$ and in the Sea of Okhotsk (see Fig. 2b).

In the South Pacific two distinct maxima are found in the model simulation: one at $\sigma=23 \mathrm{~kg} \mathrm{~m}^{-3}$ and another at $\sigma=24.8 \mathrm{~kg} \mathrm{~m}^{-3}$. The observations also show maxima, although at slightly higher density classes and less clear than in the model. The diapycnal flux toward lower densities at high $\left(\sigma=27.2 \mathrm{~kg} \mathrm{~m}^{-3}\right)$ and low densities $\left(\sigma=21.5 \mathrm{~kg} \mathrm{~m}^{-3}\right)$ are in agreement with observations. Again the cooling by the storms contributes enormously to the transformation of water masses in the midlatitudes. Without the parameterization the positive overturning cell at $\sigma=24.8 \mathrm{~kg} \mathrm{~m}^{-3}$ is almost absent. Also, there is a strong lightening of waters around $\sigma=$ $23.5 \mathrm{~kg} \mathrm{~m}^{-3}$ without storms. Finally, the negative cell around $\sigma=27.2 \mathrm{~kg} \mathrm{~m}^{-3}$ is almost entirely caused by the storms. The small negative cell around $\sigma=24 \mathrm{~kg}$ $\mathrm{m}^{-3}$ is not found in the observations although there is a local minimum at $\sigma=24.5 \mathrm{~kg} \mathrm{~m}^{-3}$. The storms contribute more to the transformation of water masses in the South Pacific than in the North Pacific. This is mainly due to the small seasonal cycle and the larger area affected in the South Pacific.

From the transformation streamfunctions it is clear that the storms have a large impact on the transformation of water masses at midlatitudes. Especially the overturning cells in the density range from $\sigma=22 \mathrm{~kg} \mathrm{~m}^{-3}$ to $25 \mathrm{~kg} \mathrm{~m}^{-3}$ are affected. The downwelling branches of these circulations correspond to the formation regions of mode waters that cover the upper part of the thermocline in the ocean. In the next section we will study how the interior is affected by the storms.

\section{2) IMPACT ON VERTICAL STRUCTURE OF THE OCEAN}

Subduction at the base of the mixed layer leads to formation of water masses. As diapycnal mixing below the mixed layer is small, the amount and the characteristics of the subducted water determine the vertical stratification of the ocean. The contribution of lateral flow through the sloping mixed layer depth in late winter to subduction can be large (Woods 1985). In the North Pacific, gradients in mixed layer depth are large in the Kuroshio region. In this area the contribution of lateral induction to the total subduction is large (Qiu and Huang 1995). The horizontal variations in the surface fluxes induce horizontal variations in the mixed layer depth. 
(a)

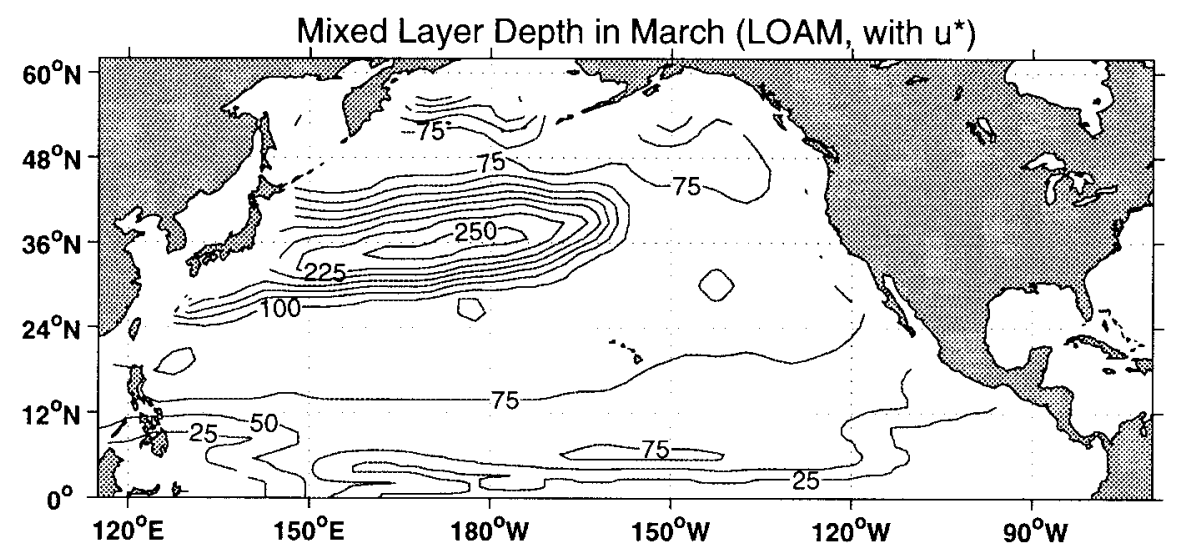

(b)

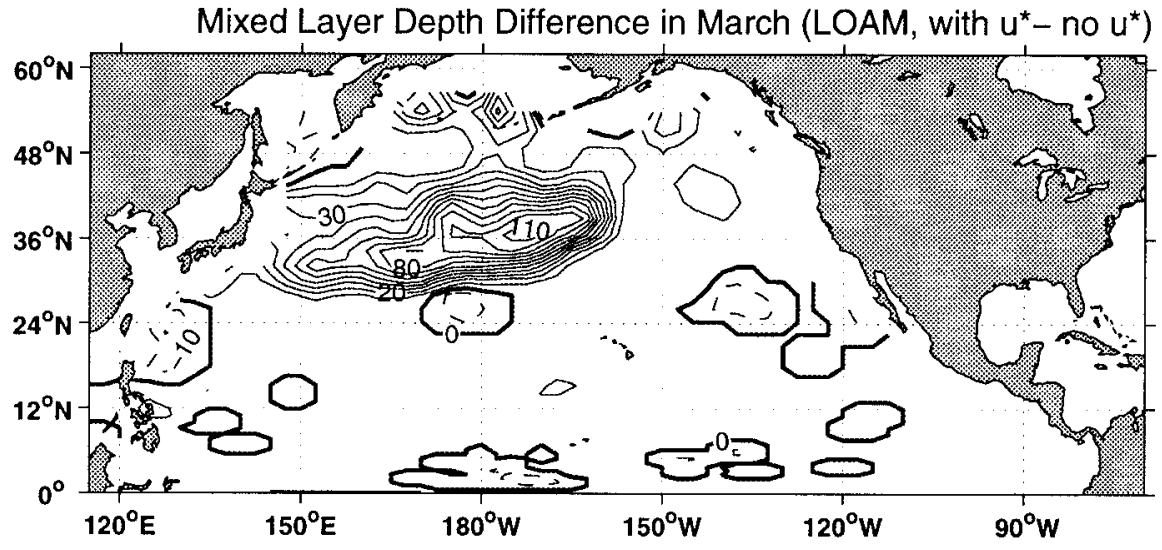

(c)

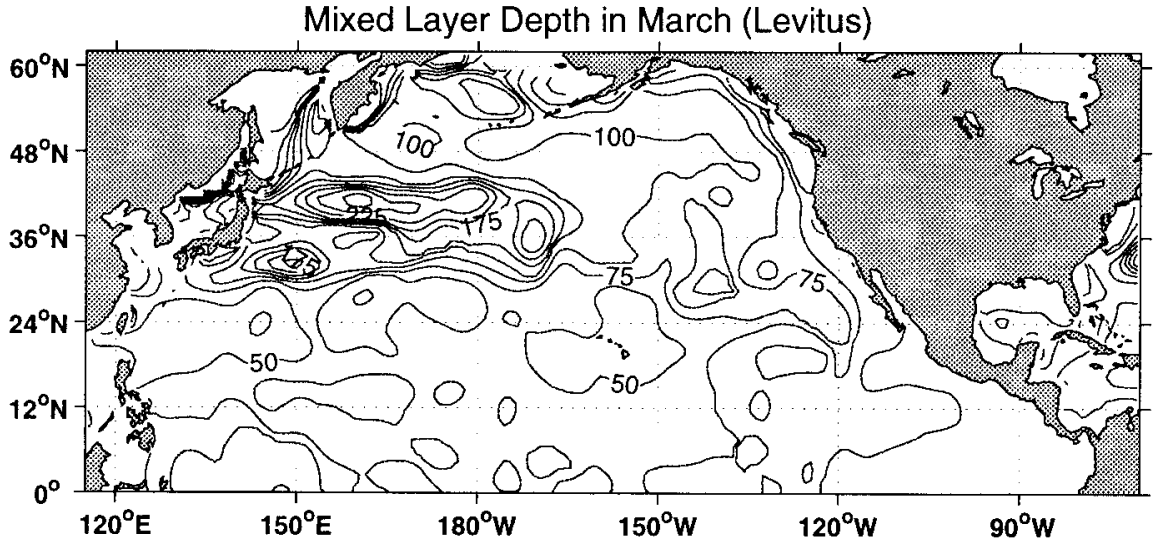

FIG. 9. Mixed layer depth (m) in March (a) model with parameterization of additional cooling due to storms, (b) difference in model with and without the parameterization, and (c) as obtained from Levitus data.

So, the cooling by the storms, which occurs in the region of high mixed layer depth gradients, is expected to have an impact on mixed layer depth and on subduction.

Indeed, the maximum mixed layer depth reaches to $250 \mathrm{~m}$ in the Kuroshio Extension when the eddy-induced transfer velocity is included, while without the extra cooling by storms the mixed layer depth reaches only to $175 \mathrm{~m}$ (Fig. 9). The maximum deepening due to the cooling by eddies is $110 \mathrm{~m}$. The observed max- imum mixed layer depths reach to $250 \mathrm{~m}$. The changes in mixed layer depth take place mainly in wintertime (Fig. 10). So, the additional eddy-induced transfer velocity leads to better simulated mixed layer depths. As the cooling enhances the transformation overturning, steepens mixed layer gradients, and increases late winter mixed layer depths, more voluminous and cooler water masses are formed when the cooling by storms is included in the model. This is clearly visible in the cross 


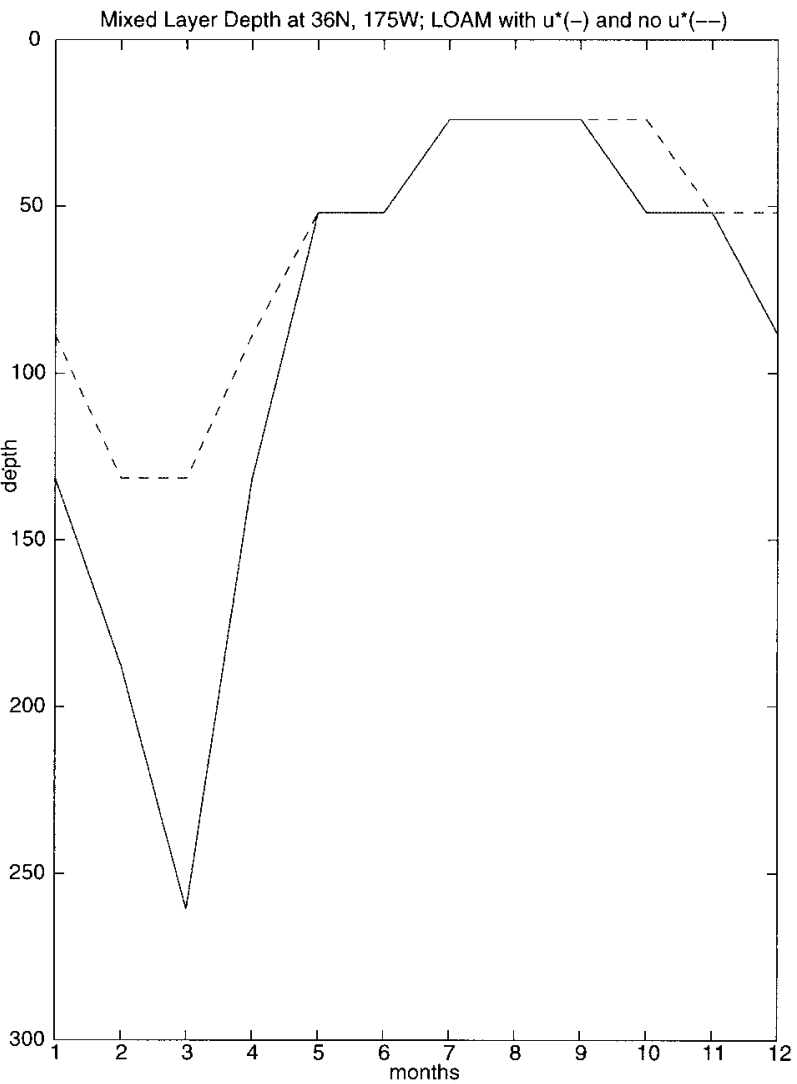

FIG. 10. Seasonal cycle of mixed layer depth (m) at $36^{\circ} \mathrm{N}, 175^{\circ} \mathrm{W}$ in the model with (continuous line) and without (dashed line) cooling by the storms.

sections of potential density shown in Fig. 11. Around $30^{\circ} \mathrm{N}$ a homogeneous water mass is found in the observations. This is the North Pacific subtropical mode water (Suga and Hanawa 1995). The core of the homogeneous layer is observed at $\sigma=25.5 \mathrm{~kg} \mathrm{~m}^{-3}$. In the model, a very distinct mode water layer is simulated between $\sigma=25.6 \mathrm{~kg} \mathrm{~m}^{-3}$ and $25.2 \mathrm{~kg} \mathrm{~m}^{-3}$ in accordance with the observations. Without the parameterization of the additional cooling by storms this homogeneous water mass is not well simulated. Also, the potential density is too low in the upper thermocline. It has been shown already in Figs. 7a and $7 b$ that the storms are responsible for the positive overturning cell associated with formation of a water mass around $\sigma=25.5 \mathrm{~kg} \mathrm{~m}^{-3}$.

In the cross sections this conclusion is confirmed. The mode water layer in the climatology is less homogeneous than in the model. However, one must take into account that a climatological forcing has been used in the model. Thus the same water mass is formed every year. In the real world, the forcing varies. This leads to varying characteristics of mode water, in accordance with variations in the forcing (Hazeleger and Drijfhout 1998). Generally, one can conclude that the storms enhance the subtropical overturning cell. More volumi- nous and denser water masses are formed in the midlatitudes due to the presence of the storm tracks.

Figure 12 shows the change in the overturning mass streamfunction in a meridional cross section. The shallow overturning increases by about $1.6 \mathrm{~Sv}$, a $10 \%$ increase. Associated changes in meridional velocities are of the order of less than a centimeter per second. Zonal velocities change by a few centimeters per second in the equatorial region. The overturning also deepens. These changes in mass transport are not very large. Large changes take place in the subsurface temperature (Fig. 13), especially in ventilated regions where cooling of a few degrees is found. These tongues with anomalous cool water clearly originate from outcrops in the midlatitudes. Even in the Tropics cooling of $1 \mathrm{~K}$ is found. Salinity hardly changes in the Tropics but increases in the directly ventilated zones (Fig. 13a). Thus, the impact of the cooling by the storms appears to be mainly of thermal nature. It is these rearrangements of density that produce the large changes in the transformation streamfunction, which produces homogeneous subsurface water masses. The changes in the salinity and temperature cause a realistic representation of the characteristics of the water masses in the ventilated thermocline.

\section{Conclusions}

A good understanding of the surface forcing of the ocean is of prime importance for climate and oceanographic studies. Here we studied one aspect of the forcing of the ocean, namely, the impact of the midlatitude storm tracks. An analysis of the moist static energy budget of the atmospheric surface layer in the Pacific region showed that the atmospheric eddies impose a cooling on the surface layer. This cooling occurs in a zonal band over the extratropical North and South Pacific. The cooling is associated with the northward heat transport in the atmosphere that is accomplished by transient eddies. The maximum cooling is found to be 60 $\mathrm{W} \mathrm{m}^{-2}$ at $170^{\circ} \mathrm{E}$. The maximum cooling by the atmospheric eddies occurs far offshore. Close to the coast the storms still develop and the surface fluxes damp the air temperature variance, maintaining strong meridional temperature gradients (Swanson and Pierrehumbert 1997). It is worth noting that this implies that parameterizing the eddy-induced transfer velocity $\left(\mathbf{u}_{*}\right)$ in terms of surface air temperature gradients does not work very well.

To study how the cooling by the storms affect the surface and subsurface layers of the ocean, an ocean model coupled to a model of the atmospheric mixed layer has been used. A parameterization of the impact of the eddies on the heat budget of the surface layer has been implemented that is based on a parameterization of eddies in the ocean. The storms are represented by an eddy-induced transfer velocity that is added to the Eulerian mean velocity. In this study the eddy-induced 
(a)

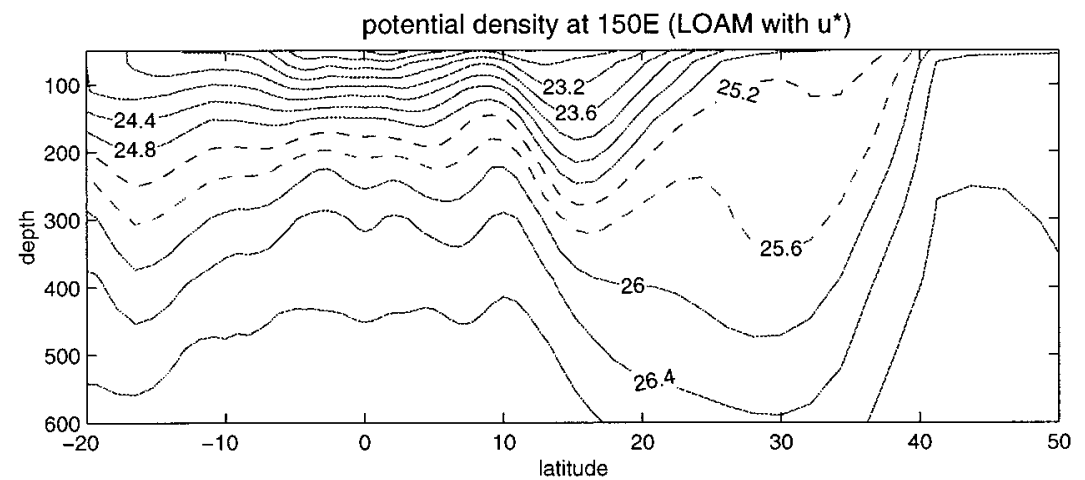

(b)

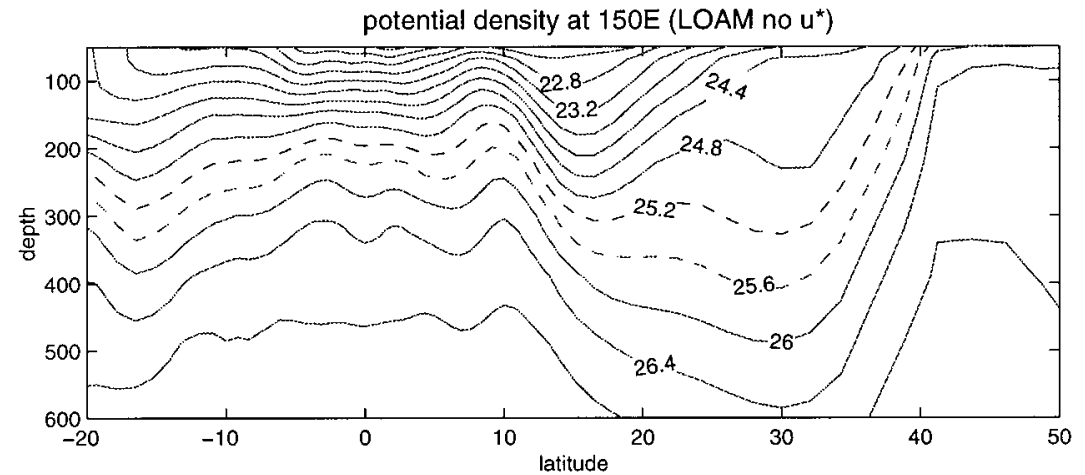

(c)

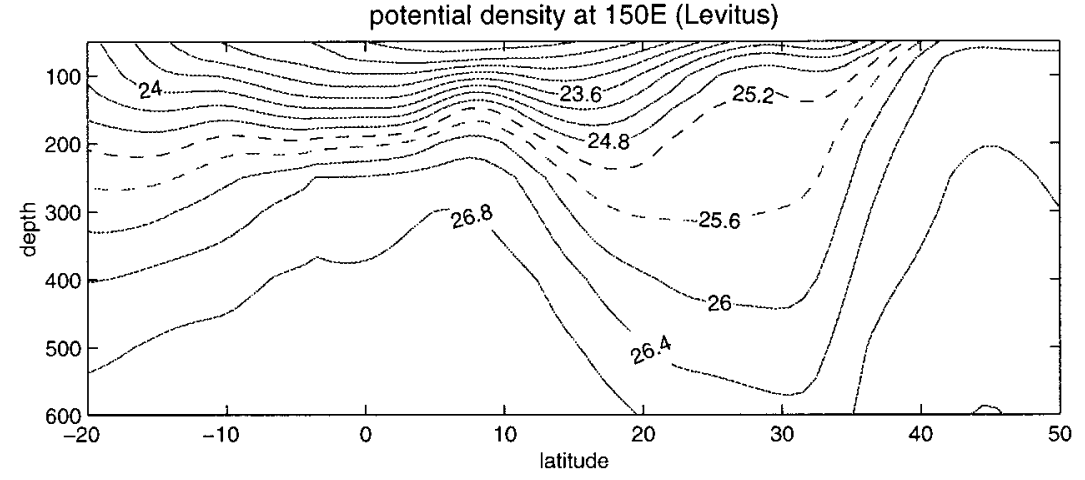

FIG. 11. Cross section of potential density $\left(\mathrm{kg} \mathrm{m}^{-3}\right)$ in Sep in (a) the model with and (b) without parameterization of additional cooling due to storms and (c) according to Levitus data at $150^{\circ} \mathrm{E}$ The isopycnals where mode water is observed are dashed.

transfer velocity has been specified according to the NCEP-NCAR reanalysis data. The simulated eddy transports of air temperature and humidity by the atmospheric mixed layer model are in good agreement with the observed eddy transports. To study the effect of storm tracks on oceanic variables the coupled model has been run with and without the eddy-induced transfer velocity.

The enhanced heat fluxes from the ocean to the atmosphere lead to SSTs that are $3 \mathrm{~K}$ lower in the midlatitudes. Overall the surface characteristics of the ocean are more realistically simulated when the cooling by the storms is included. However, in the boreal summer a relatively large error has been induced in the subtropical regions. This deficiency may be attributed to errors in the wind climatology in this region. The cooling attributable to the storms makes surface waters less buoyant, which leads to deeper mixed layers in the midlatitudes. This results in an increased subduction of denser water in late winter. As a result the shallow overturning is more intense and more voluminous water masses are formed. The homogeneous mode waters that dominate the stratification in the subtropical gyre are especially well simulated when the cooling effect of storms is accounted for. As the subtropical meridional overturning cell is enhanced by the eddies and cooler water is subducted, even the tropical regions are affected. Although the storms do not directly affect the surface layers here, the upwelling branch of the overturning cell connects the midlatitudes to the (sub)tropics. As a result of the 
(a)

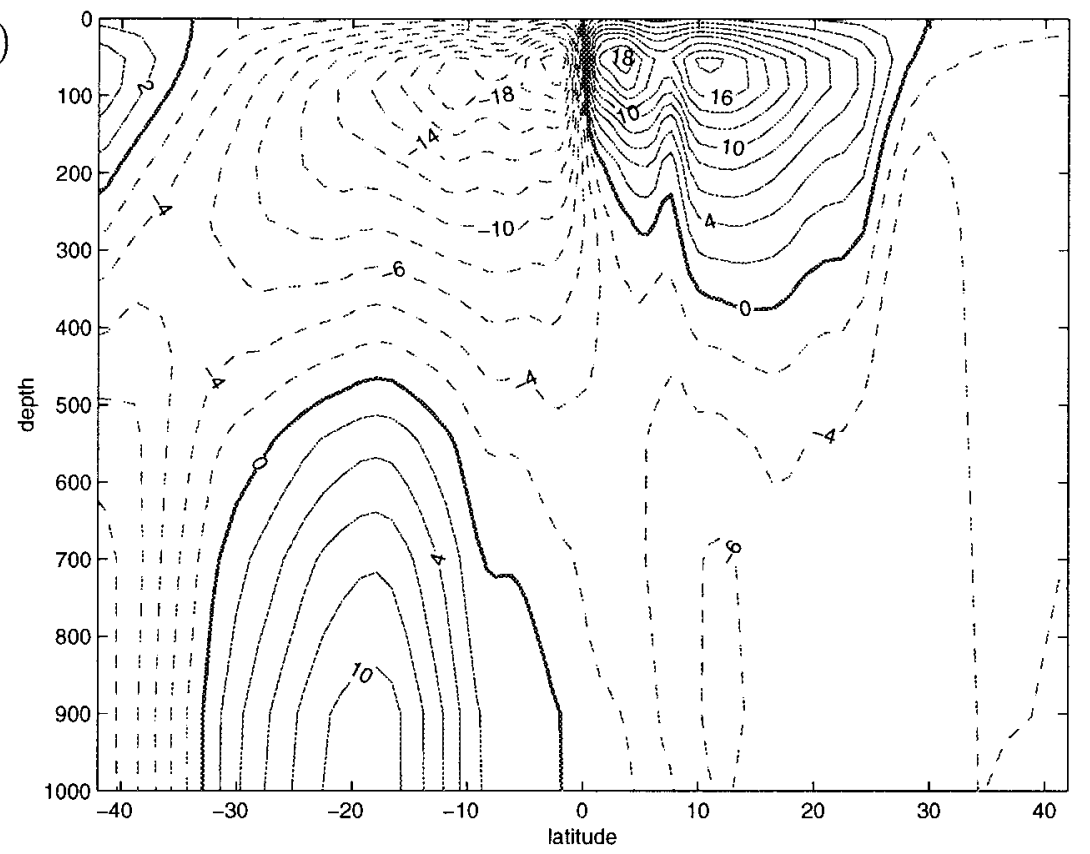

(b)

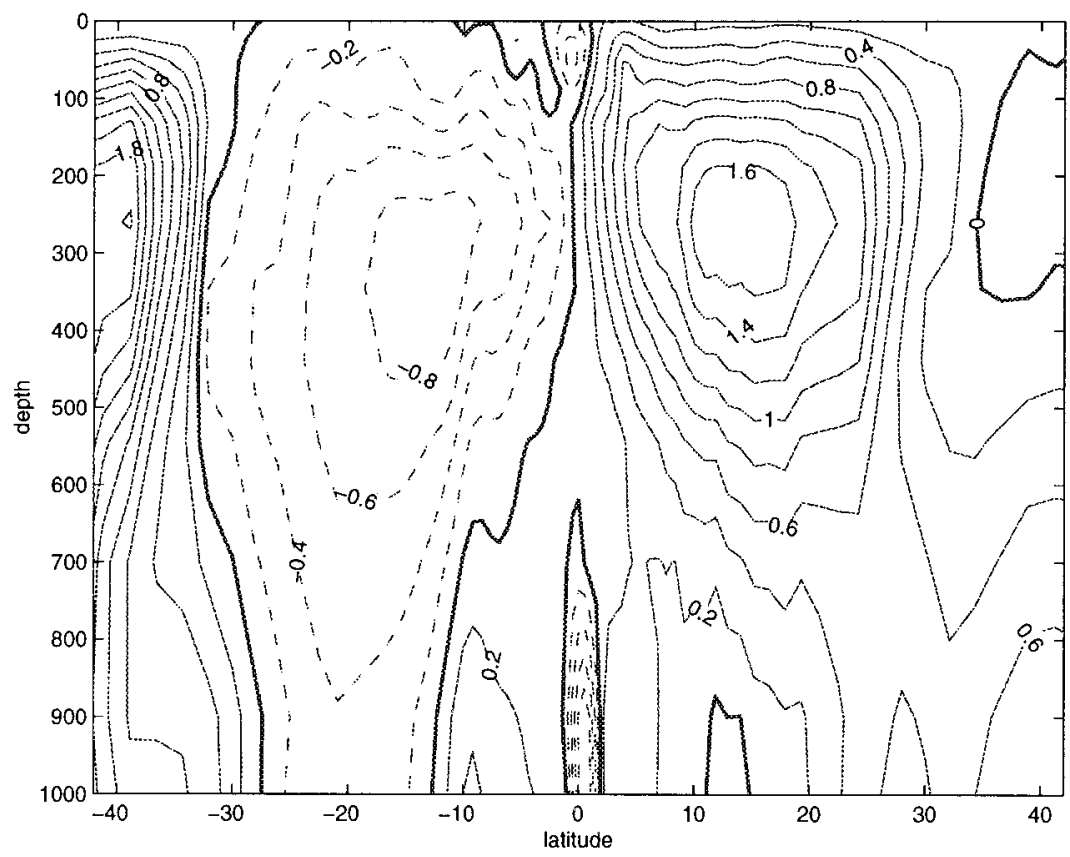

FIG. 12. Zonally averaged overturning streamfunction (Sv) in (a) model with cooling due to the storms and (b) the difference in the model with and without the additional cooling.

change in the meridional cell, even tropical SSTs are affected. This mechanism leaves open the possibility of midlatitude variability influencing tropical variability via an oceanic bridge, as has been suggested by Gu and Philander (1997).

In conclusion, the cooling by the atmospheric storm tracks contributes significantly to the heat budget of the midlatitude atmospheric surface layer. Its effect on the surface and subsurface layers of the ocean has been shown to be substantial. As such, a parameterization of the impact of atmospheric storms on the surface heat budget is essential when ocean models are coupled to simple atmospheric models that do not include the impact of transient eddies. The effect of the atmospheric 
(a)

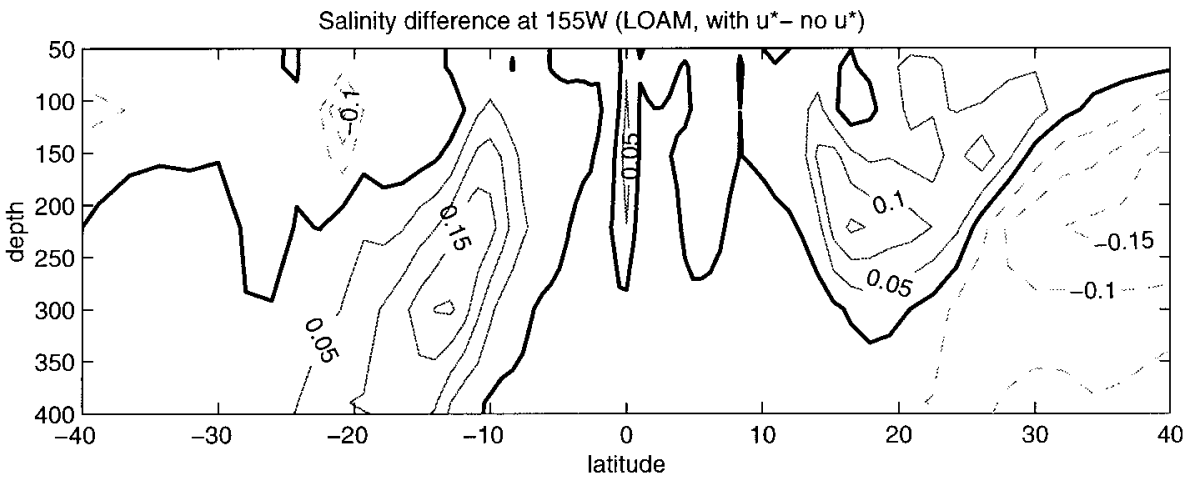

(b)

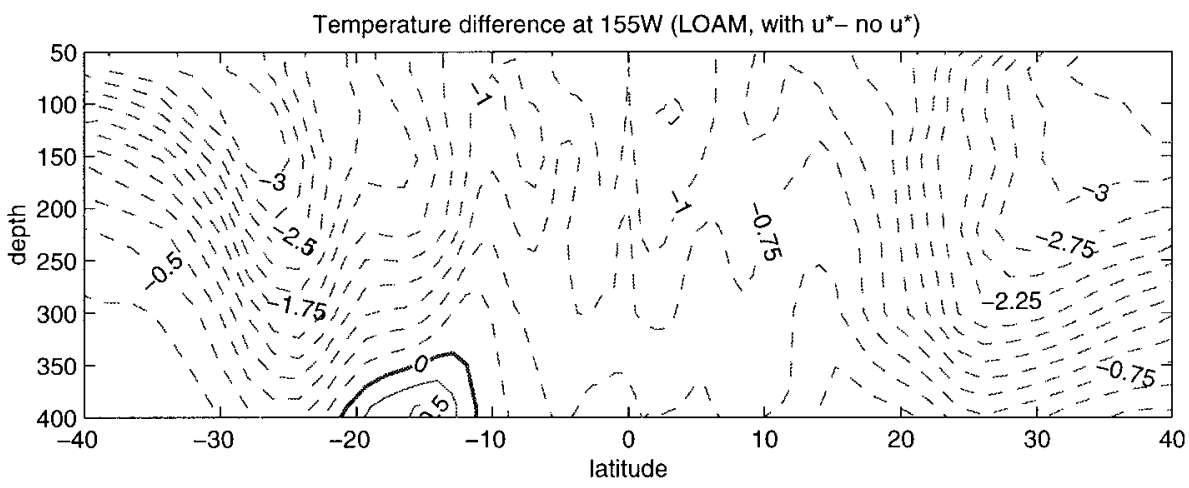

FIG. 13. Meridional cross section of impact of the cooling by storms on (a) the salinity (psu) and (b) temperature $(\mathrm{K})$.

eddies can be represented well by an eddy-induced transfer velocity. The next challenge will be to develop a parameterization of turbulent entrainment at the top of the atmospheric mixed layer. In addition, there is also the challenge of relating variability in the storm tracks to that of the underlying SST. We plan to study these issues in the near future.

Acknowledgments. The authors would like to thank Benno Blumenthal for pioneering work on the subject of this paper. This work was sponsored by NOAA (UCSIO-10775411D/NA47GP0188, "The Consortium on the Ocean's Role in Climate") and NSF (ATM-9224915). W.H. likes to thank the people of the Climate and the Physical Oceanography group of Lamont Doherty Earth Observatory for their hospitality and stimulating atmosphere during his stay. Furthermore, KNMI is thanked for the opportunity and financial support of the visit.

\section{REFERENCES}

Alexander, M. A., and S. D. Schubert, 1990: Regional earth-atmosphere energy balance estimates based on assimilations with a GCM. J. Climate, 3, 15-31.

- , and J. D. Scott, 1997: Surface flux variability over the North Pacific and North Atlantic Oceans. J. Climate, 10, 2963-2978.

Bishop, J. K. B., and W. B. Roswow, 1991: Spatial and temporal variability of global surface solar irradiance. J. Geophys. Res., 96, $16839-16858$.
Boers, R., and A. K. Betts, 1988: Saturation point structure of marine stratocumulus clouds. J. Atmos. Sci., 45, 1156-1175.

Camp, N. T., and R. L. Elsberry, 1978: Oceanic thermal response to strong atmospheric forcing. II: The role of one-dimensional processes. J. Phys. Oceanogr., 8, 215-224.

Cayan, D., 1992: Latent and sensible heat flux anomalies over the northern oceans: Driving the sea surface temperature. J. Phys. Oceanogr., 22, 541-560.

Da Silva, A. M., C. C. Young, and S. Levitus, 1994: Atlas of Surface Marine Data 1994, Vol. 1: Algorithms and Procedures, NOAA/ NESDIS Atlas 6, U.S. Department of Commerce, NOAA, NESDIS, 83 pp.

Gent, P. R., and J. C. McWilliams, 1990: Isopycnal mixing in ocean circulation models. J. Phys. Oceanogr., 20, 150-155.

Grossman, R. L., and A. K. Betts, 1990: Air-sea interaction during an extreme cold air outbreak from the eastern coast of the United States. Mon. Wea. Rev., 118, 324-342.

Gu, D. F., and S. G. H. Philander, 1997: Interdecadal climate fluctuations that depend on exchanges between the Tropics and extratropics. Science, 275, 805-807.

Hazeleger, W., and S. S. Drijfhout, 1998: Mode water variability in a model of the subtropical gyre: Response to anomalous forcing. J. Phys. Oceanogr., 28, 266-288.

Johnson, G., and M. McPhaden, 1999: Interior pycnocline flow from the subtropical to the equatorial Pacific Ocean. J. Phys. Oceanogr., 29, 3073-3089.

Kalnay, E., and Coauthors, 1996: The NCEP/NCAR 40-Year Reanalysis Project. Bull. Amer. Meteor. Soc., 77, 437-471.

Kleeman, R., and S. B. Power, 1995: A simple atmospheric model of surface heat flux for use in ocean modeling studies. J. Phys. Oceanogr., 25, 92-105.

Kushner, P. J., and I. M. Held, 1998: A test, using atmospheric data, of a method for estimating oceanic eddy diffusivity. Geophys. Res. Lett., 25, 4213-4216.

Latif, M., and T. P. Barnett, 1994: Causes of decadal climate vari- 
ability over the North Pacific and North America. Science, 266, 634-637.

Lau, N., 1988: Variability of the observed midlatitude storm tracks in relation to low-frequency changes in the circulation pattern. J. Atmos. Sci., 45, 2718-2743.

Levitus, S., and T. P. Boyer, 1994. World Ocean Atlas 1994, Vol. 4: Temperature. NOAA Atlas NESDIS, U.S. Govt. Printing Office, $117 \mathrm{pp}$.

— R. Burgett, and T. P. Boyer, 1994: World Ocean Atlas 1994 Vol. 3: Salinity. NOAA Atlas NESDIS, U.S. Govt. Printing Office, 99 pp.

Marsh, R., A. J. Nurser, A. P. Mergann, and A. L. New, 2000: Water mass transformation in the Southern Ocean of a global isopycna coordinate GCM. J. Phys. Oceanogr., 30, 1013-1045.

Marshall, J. C., D. Jamous, and J. Nilsson, 1999: Reconciling 'thermodynamic' and 'dynamic' methods of computation of water mass transformation rates. Deep-Sea Res., 46, 545-572.

Murtugudde, R., R. Seager, and A. J. Busalacchi, 1996: Simulation of the tropical oceans with an ocean GCM coupled to an atmospheric mixed layer model. J. Climate, 9, 1795-1815.

Naik, N. H, M. A. Cane, S. Basin, and M. Israeli, 1995: A solver for the barotropic mode in the presence of variable topography and islands. Mon. Wea. Rev., 123, 817-832.

Nurser, A. J. G., R. Marsh, and R. G. Williams, 1999: Diagnosing water mass transformation from air-sea fluxes and surface mixing. J. Phys. Oceanogr., 29, 1468-1487.

Polonsky, A. B., S. A. Baev, and A. Diakite, 1992: On the response of the ocean upper layer to synoptic variability of the atmosphere. Dyn. Atmos. Oceans, 16, 225-248.

Qiu, B., and R. X. Huang, 1995: Ventilation of the North Atlantic and North Pacific: Subduction versus obduction. J. Phys. Oceanogr., 25, 2374-2390.

Rodgers, K. B., M. A. Cane, N. H. Naik, and D. P. Schrag, 1999 The role of the Indonesian Throughflow in equatorial Pacific thermocline ventilation. J. Geophys. Res., 104, 20 551-20 570.
Rothstein, L. M., R. Zhang, A. J. Bussalacchi, and D. Chen, 1998: A numerical simulation of the mean water pathways in the subtropical and tropical Pacific Ocean. J. Phys. Oceanogr., 28, 322343.

Seager, R., M. B. Blumenthal, and Y. Kushnir, 1995: An advective atmospheric mixed layer model for ocean modeling purposes: Global simulation of surface heat fluxes. J. Climate, 8, 19511964.

_, Y. Kushnir, M. Visbeck, N. Naik, J. Miller, G. Krahmann, and H. Cullen, 2000: Causes of Atlantic Ocean climate variability between 1958 and 1998. J. Climate, 13, 2845-2862.

Speer, K., and E. Tziperman, 1992: Rates of water mass formation in the North Atlantic Ocean. J. Phys. Oceanogr., 22, 93-104.

Suga, T., and K. Hanawa, 1995: The subtropical mode water circulation in the North Pacific. J. Phys. Oceanogr., 25, 958-970.

Swanson, K. L., and R. T. Pierrehumbert, 1997: Lower-tropospheric heat transport in the Pacific storm track. J. Atmos. Sci., 54, 15331543.

Valdes, P., and B. J. Hoskins, 1989: Linear stationary wave simulations of the time-mean climatological flow. J. Atmos. Sci., 46, $2509-2527$

Visbeck, M., J. Marshall, T. Haine, and M. Spall, 1997: Specification of eddy transfer coefficients in coarse resolution ocean circulation models. J. Phys. Oceanogr., 27, 381-402.

- H. Cullen, G. Krahmann, and N. Naik, 1998: An ocean models response to North Atlantic Oscillation-like wind forcing. Geophys. Res. Lett., 25, 4521-4524.

Walin, G., 1982: On the relation between sea-surface heat flow and thermal circulation in the ocean. Tellus, 34, 187-195.

Wallace, J. M., G. H. Lim, and M. L. Blackmon, 1988: Relationship between cyclone tracks, anticyclone tracks, and baroclinic wave guides. J. Atmos. Sci., 45, 439-462.

Woods, J. D., 1985: The physics of thermocline ventilation. Coupled Ocean-Atmosphere Models, J. C. J. Nihoul, Ed., Elsevier, 543590. 